Atmos. Chem. Phys., 18, 11041-11071, 2018

https://doi.org/10.5194/acp-18-11041-2018

(C) Author(s) 2018. This work is distributed under

the Creative Commons Attribution 4.0 License.
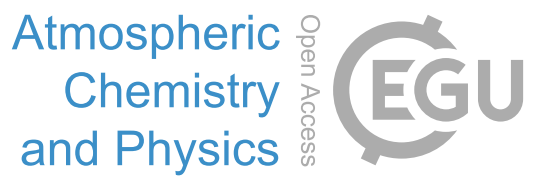

\title{
A model intercomparison of CCN-limited tenuous clouds in the high Arctic
}

\author{
Robin G. Stevens ${ }^{1, \mathrm{a}}$, Katharina Loewe ${ }^{2}$, Christopher Dearden ${ }^{3, \mathrm{~b}}$, Antonios Dimitrelos ${ }^{4}$, Anna Possner ${ }^{5,6}$, \\ Gesa K. Eirund $^{5}$, Tomi Raatikainen ${ }^{7}$, Adrian A. Hill ${ }^{8}$, Benjamin J. Shipway ${ }^{8}$, Jonathan Wilkinson ${ }^{8}$, \\ Sami Romakkaniemi ${ }^{9}$, Juha Tonttila ${ }^{9}$, Ari Laaksonen ${ }^{7}$, Hannele Korhonen ${ }^{7}$, Paul Connolly ${ }^{3}$, Ulrike Lohmann ${ }^{5}$, \\ Corinna Hoose $^{2}$, Annica M. L. Ekman ${ }^{4}$, Ken S. Carslaw ${ }^{1}$, and Paul R. Field ${ }^{1,8}$ \\ ${ }^{1}$ Institute of Climate and Atmospheric Science, School of Earth and Environment, University of Leeds, Leeds, UK \\ ${ }^{2}$ Institute of Meteorology and Climate Research, Karlsruhe Institute of Technology, Karlsruhe, Germany \\ ${ }^{3}$ Centre for Atmospheric Science, School of Earth and Environmental Sciences, University of Manchester, Manchester, UK \\ ${ }^{4}$ Department of Meteorology, Stockholm University, Stockholm, Sweden \\ ${ }^{5}$ Institute for Atmospheric and Climate Science, Eidgenössische Technische Hochschule, Zürich, Switzerland \\ ${ }^{6}$ Department of Global Ecology, Carnegie Institution for Science, Stanford, CA, USA \\ ${ }^{7}$ Finnish Meteorological Institute, Helsinki, Finland \\ ${ }^{8}$ Met Office, Exeter, UK \\ ${ }^{9}$ Finnish Meteorological Institute, Kuopio, Finland \\ ${ }^{a}$ now at: Air Quality Research Division, Environment and Climate Change Canada, Dorval, Canada \\ bnow at: the Centre of Excellence for Modelling the Atmosphere and Climate, School of Earth and Environment, \\ University of Leeds, Leeds, UK
}

Correspondence: Robin G. Stevens (robin.stevens@canada.ca)

Received: 5 December 2017 - Discussion started: 11 December 2017

Revised: 23 June 2018 - Accepted: 26 June 2018 - Published: 8 August 2018

\begin{abstract}
We perform a model intercomparison of summertime high Arctic $\left(>80^{\circ} \mathrm{N}\right)$ clouds observed during the 2008 Arctic Summer Cloud Ocean Study (ASCOS) campaign, when observed cloud condensation nuclei $(\mathrm{CCN})$ concentrations fell below $1 \mathrm{~cm}^{-3}$. Previous analyses have suggested that at these low $\mathrm{CCN}$ concentrations the liquid water content (LWC) and radiative properties of the clouds are determined primarily by the $\mathrm{CCN}$ concentrations, conditions that have previously been referred to as the tenuous cloud regime. The intercomparison includes results from three large eddy simulation models (UCLALES-SALSA, COSMO-LES, and MIMICA) and three numerical weather prediction models (COSMO-NWP, WRF, and UM-CASIM). We test the sensitivities of the model results to different treatments of cloud droplet activation, including prescribed cloud droplet number concentrations (CDNCs) and diagnostic CCN activation based on either fixed aerosol concentrations or prognostic aerosol with in-cloud processing.
\end{abstract}

There remains considerable diversity even in experiments with prescribed CDNCs and prescribed ice crystal number concentrations (ICNC). The sensitivity of mixed-phase Arctic cloud properties to changes in CDNC depends on the representation of the cloud droplet size distribution within each model, which impacts autoconversion rates. Our results therefore suggest that properly estimating aerosol-cloud interactions requires an appropriate treatment of the cloud droplet size distribution within models, as well as in situ observations of hydrometeor size distributions to constrain them.

The results strongly support the hypothesis that the liquid water content of these clouds is CCN limited. For the observed meteorological conditions, the cloud generally did not collapse when the $\mathrm{CCN}$ concentration was held constant at the relatively high $\mathrm{CCN}$ concentrations measured during the cloudy period, but the cloud thins or collapses as the $\mathrm{CCN}$ concentration is reduced. The $\mathrm{CCN}$ concentration at which collapse occurs varies substantially between models. 
Only one model predicts complete dissipation of the cloud due to glaciation, and this occurs only for the largest prescribed ICNC tested in this study. Global and regional models with either prescribed CDNCs or prescribed aerosol concentrations would not reproduce these dissipation events. Additionally, future increases in Arctic aerosol concentrations would be expected to decrease the frequency of occurrence of such cloud dissipation events, with implications for the radiative balance at the surface. Our results also show that cooling of the sea-ice surface following cloud dissipation increases atmospheric stability near the surface, further suppressing cloud formation. Therefore, this suggests that linkages between aerosol and clouds, as well as linkages between clouds, surface temperatures, and atmospheric stability need to be considered for weather and climate predictions in this region.

\section{Introduction}

A decrease in Arctic sea-ice extent and thickness has been observed within recent decades (Vaughan et al., 2013). Further decreases in Arctic sea-ice extent are expected to increase the fluxes of aerosol and aerosol precursor gases (Struthers et al., 2011; Corbett et al., 2010) as well as latent heat and sensible heat from the open ocean surface within the Arctic (Boisvert and Stroeve, 2015). The long-range transport of anthropogenic aerosol is currently a significant source to the Arctic region (Sand et al., 2017; Shindell and Faluvegi, 2009). Therefore, future changes in non-local sources of aerosol and long-range transport could have significant impacts on aerosol concentrations in the Arctic. Furthermore, an increase in shipping traffic is expected once the Arctic becomes seasonally ice free, further increasing aerosol concentrations (Peters et al., 2011). This increase in shipping traffic would also be expected to yield an increased demand for accurate weather forecasts over the Arctic region. However, it remains unclear whether the net effect of these changes in aerosol concentrations and surface fluxes would result in an increase or a decrease in cloud cover or drizzle precipitation. Changes in cloud properties could strongly influence the radiation budget in the Arctic, resulting in feedbacks on the rate of sea-ice loss. Arctic clouds remain poorly understood, and the current representation of these processes in global climate models is most likely insufficient to realistically simulate long-term changes.

Few observations have been made of Arctic clouds relative to clouds at lower latitudes. Field campaigns that have investigated Arctic clouds include the International Arctic Ocean Expeditions in 1991 (AOE-91; Leck et al., 1996) and 1996 (AOE-96; Leck et al., 2001), the Arctic Ocean Experiment in 2001 (AOE-01; Leck et al., 2004; Tjernström et al., 2004), the First ISCCP (International Satellite Cloud Climatology Project) Regional Experiment-Arctic Clouds Ex- periment in 1998 (FIRE-ACE; Curry et al., 2000), the Surface Heat Budget of the Arctic Ocean project in 1997-1998 (SHEBA; Uttal et al., 2002), the Mixed-Phase Arctic Cloud Experiment in 2004 (M-PACE; Verlinde et al., 2007), the Indirect and Semi-Direct Aerosol Campaign in 2008 (ISDAC; McFarquhar et al., 2011), the Arctic Summer Cloud Ocean Study in 2008 (ASCOS; Tjernström et al., 2014), the VERtical Distribution of Ice in Arctic cloud campaign in 2012 (VERDI; Klingebiel et al., 2015), the Aerosol-Cloud Coupling and Climate Interactions in the Arctic campaign in 2013 (ACCACIA; Lloyd et al., 2015; Young et al., 2016), the Arctic Clouds in Summer Experiment in 2014 (ACSE Tjernström et al., 2015), and the Canadian Network on Climate and Aerosols: Addressing Key Uncertainties in Remote Canadian Environment campaign in 2014 (NETCARE; Leaitch et al., 2016). Of these campaigns, only a few (AOE91, AOE-96, AOE-01, ASCOS, and ACSE) have sampled the high Arctic north of $80^{\circ} \mathrm{N}$. These campaigns and subsequent analyses have provided insights into the structures and radiative impacts of Arctic clouds, including the following.

1. At supersaturations as high as $0.8 \%$, observed cloud condensation nuclei $(\mathrm{CCN})$ concentrations are usually less than $100 \mathrm{~cm}^{-3}$ in the high Arctic summer and have been observed to be as low as $1 \mathrm{~cm}^{-3}$ (Bigg et al., 1996; Bigg and Leck, 2001; Lannerfors et al., 1983; Leck et al., 2002; Leck and Svensson, 2015; Mauritsen et al., 2011). During the AOE-91, AOE-96, AOE01 , and ASCOS campaigns more than $25 \%$ of observed $\mathrm{CCN}$ concentrations were $<10 \mathrm{~cm}^{-3}$ at supersaturations $\leq 0.3 \%$. Additionally, more than $60 \%$ of the lowaltitude clouds observed via aircraft during the NETCARE campaign were found to have $\mathrm{CCN}$ concentrations less than $16 \mathrm{~cm}^{-3}$ at a supersaturation of $0.6 \%$ (Leaitch et al., 2016).

2. Arctic clouds often have a net warming effect on the surface, even in summer (Intrieri et al., 2002). The shortwave (SW) radiative effect of Arctic clouds is small relative to the longwave (LW) radiative effect due to the high albedo of sea ice and the low angle of incoming solar radiation.

3. The LW surface warming effect of Arctic clouds strongly affects the surface temperature and therefore would be expected to impact the thickness and extent of Arctic sea ice (Curry et al., 1993; Kapsch et al., 2016).

In order to better understand the processes controlling Arctic clouds and their uncertainties in current models, we perform a model intercomparison of summertime high Arctic $\left(>80^{\circ} \mathrm{N}\right)$ clouds. We have chosen as our case study the final 2 days of the ice drift period of the 2008 ASCOS campaign (Paatero et al., 2009; Tjernström et al., 2014). During this period, a decrease in cloud water content was observed coincident with a decrease in observed $\mathrm{CCN}$ concentrations 
to less than $1 \mathrm{~cm}^{-3}$. The concentrations of $\mathrm{CCN}$ were measured continuously using a CCN counter operating at a fixed supersaturation of $\sim 0.2 \%$. Details on the quality and data processing of ship-based CCN measurements are available in Martin et al. (2011) and in Leck and Svensson (2015).

Previous analysis (Birch et al., 2012; Mauritsen et al., 2011) has identified these clouds as existing within the tenuous cloud regime: cloud liquid water content (LWC) and surface radiative effects are limited by the availability of aerosol to act as $\mathrm{CCN}$. This cloud regime has been observed during the ASCOS campaign (Mauritsen et al., 2011) and the NETCARE campaign (Leaitch et al., 2016). Due to the low $\mathrm{CCN}$ concentrations observed in the high Arctic, this cloud regime is expected to be a frequent occurrence in the Arctic summer. Sedlar et al. (2011) have linked the dissipation of these clouds and the associated increase in surface LW cooling to the onset of the autumn sea-ice freeze-up in 2008. The tenuous cloud regime would be very sensitive to changes in aerosol concentrations due to increased emissions from either increased human activity in the Arctic or increased emissions due to decreasing sea ice. Changes in these clouds would be expected to affect the surface radiative energy balance and thereby potentially affect Arctic sea-ice extent and thickness. The tenuous cloud regime therefore presents an important but challenging case to represent within models.

The ASCOS ice drift period, in whole or in part, has been previously examined using models by Birch et al. (2012), Wesslén et al. (2014), Sotiropoulou et al. (2015), Hines and Bromwich (2017), Loewe et al. (2017), and Igel et al. (2017). The models used by these studies were a singlecolumn model configuration of the Met Office Unified Model (UM), two versions of the Arctic System Reanalysis (ASR) and the ERA-Interim reanalysis, the Integrated Forecast System (IFS) model of the European Centre for Medium-Range Weather Forecasts (ECMWF), the polar-optimized version of the Weather Research and Forecasting (WRF) regional numerical weather prediction (NWP) model, the Consortium for Small-scale Modeling (COSMO) model configured as a large eddy simulation (LES) model, and the MISU MIT Cloud and Aerosol (MIMICA) LES model, respectively. Birch et al. (2012) found that observations of surface radiative fluxes and surface temperatures were better reproduced by the single-column UM during the tenuous cloud regime period on 1 September 2008 if prescribed CCN concentrations were reduced to $1 \mathrm{~cm}^{-3}$. For higher $\mathrm{CCN}$ concentrations, the model produced cloud with much larger LWCs than observed. Wesslén et al. (2014) highlighted the fact that the two configurations of ASR failed to reproduce the observed clouds from 27 August to 1 September. They noted that this period was better represented by ERA-Interim, and they hypothesized that this was due to differences in the treatment of cloud microphysics. Sotiropoulou et al. (2015) found that, while using a constant assumed CCN concentration, increased model vertical resolution and a newer cloud microphysics scheme including prognostic cloud ice, rain and snow were insufficient to reproduce cloud dissipation during the tenuous cloud periods. Similarly to Birch et al. (2012), Hines and Bromwich (2017) found that biases of the Polar WRF regional NWP model against surface radiative flux observations for the entire ASCOS drift period were reduced as the prescribed cloud droplet number concentration (CDNC) was reduced from values representative of low latitudes $\left(250 \mathrm{~cm}^{-3}\right)$ to values representative of pristine Arctic conditions $\left(10 \mathrm{~cm}^{-3}\right)$. Biases during the periods labelled as in the tenuous cloud regime were further reduced if the prescribed CDNC was reduced to $1 \mathrm{~cm}^{-3}$. Loewe et al. (2017) found that in the LES configuration of COSMO, a prescribed CDNC of $2 \mathrm{~cm}^{-3}$ was insufficient to prevent cloud dissipation but that a cloud could be maintained with a prescribed CDNC of $10 \mathrm{~cm}^{-3}$. They additionally performed sensitivity studies to moisture availability and to ice crystal number concentrations (ICNCs). The cloud LWC was found to be sensitive to both moisture availability and ICNC, but none of the tested water vapour profiles resulted in cloud dissipation, and an unrealistically high ICNC was required for cloud glaciation. Using the MIMICA LES model, Igel et al. (2017) found that enhanced levels of accumulation-mode particles, if located at the cloud top, may under certain conditions be an important source of accumulation-mode particles in the Arctic boundary layer.

Previous model studies of other Arctic mixed-phase clouds have established the sensitivity of cloud LWC, ice water contents (IWC), and other cloud properties in models to the interaction of ice and liquid (Klein et al., 2009), the representation of ice enhancement mechanisms (Fan et al., 2009), prescribed cloud ICNC (Morrison et al., 2003, 2011; Ovchinnikov et al., 2011, 2014; Prenni et al., 2007; Solomon et al., 2009), ice-nucleating particle (INP) concentrations (Avramov and Harrington, 2010; Harrington et al., 1999; Jiang et al., 2000; Morrison et al., 2005b; Pinto, 1998; Possner et al., 2017; Prenni et al., 2007; Young et al., 2017), INP depletion and supply (Fridlind et al., 2012; Morrison et al., 2005b; Paukert and Hoose, 2014; Possner et al., 2017; Prenni et al., 2007; Solomon et al., 2015), the size distribution of cloud ice (Ovchinnikov et al., 2014), the habit of cloud ice (Avramov and Harrington, 2010; Fridlind et al., 2012), and enhancement of CCN concentrations by ship emissions (Possner et al., 2017). Additionally, Furtado and Field (2017) have investigated the importance of riming in mixed-phase clouds. However, the clouds investigated in these studies had greater CDNCs and would not be expected to show the same sensitivity to changes in $\mathrm{CCN}$ concentrations as the tenuous cloud regime observed during ASCOS.

In this paper, we extend these previous studies by comparing the results of both LES and cloud-resolving NWP models of the tenuous cloud regime observed during ASCOS using increasingly complex representations of aerosolcloud interactions. We begin with simulations of liquid-phase cloud only, and we later show results in which ice nucleation is included through prescribed ICNCs. We show first 
the results of simulations in which cloud droplet activation is represented using prescribed CDNCs, similar to the studies of Birch et al. (2012), Loewe et al. (2017), and Hines and Bromwich (2017). We then show the results of simulations with cloud droplet activation calculated based on a temporally and spatially constant aerosol size distribution. Finally, we include in our simulations prognostic aerosol concentrations, including aerosol uptake and removal by activation into cloud droplets, which reduces the available $\mathrm{CCN}$ for activation in subsequent model time steps. In this way, we attempt to determine the key processes contributing to the dissipation of these clouds, and we isolate and attempt to attribute differences in model results to differences in model processes. We then discuss the implications for realistic representation of Arctic aerosol-cloud interactions.

Section 2 shows an overview of observed meteorological conditions during the case study period. Section 3 describes the models participating in this study. Section 4 describes the simulations performed for this study. Section 5 presents and discusses the results of our liquid-phase-only simulations, and Sect. 6 presents and discusses the results of the simulations including cloud ice. Finally, Sect. 7 offers a summary and our conclusions.

\section{Overview of the ASCOS campaign}

A full description of the conditions during the ASCOS campaign is available in Tjernström et al. (2012). Observations during the ASCOS campaign were obtained on-board the icebreaker Oden from two measurement sites set up on the ice floe and by helicopter. However, helicopter observations were restricted to outside of clouds due to safety concerns regarding icing of the aircraft. In order to examine the tenuous cloud regime, we focus our study on the period from $30 \mathrm{Au}-$ gust to 1 September 2008. These were the last 2 days of the ice drift period, which ended at about $87^{\circ} 09 \mathrm{~N}, 11^{\circ} 01 \mathrm{~W}$. Observed winds were westerly at the site, with observed wind speeds varying between 2 and $6 \mathrm{~m} \mathrm{~s}^{-1}$ during the 2-day period. Conditions were dominated by a high-pressure system over the North Pole, yielding anticyclonic winds on the synoptic scale. Observed surface pressures rose from $\sim 1025$ to $\sim 1030 \mathrm{hPa}$ during the 2-day period. Mixed-phase stratocumulus clouds were observed during this period until approximately 20:00 UTC on 31 August, when a break in low-level cloud cover was observed, despite observed water vapour mixing ratios at or above saturation coincident with a decrease in observed CCN concentrations from about 70 to $<1 \mathrm{~cm}^{-3}$ (Mauritsen et al., 2011). The CCN concentrations were measured continuously using a $\mathrm{CCN}$ counter operating at a fixed supersaturation of $\sim 0.2 \%$. A second identical CCN counter was cycled between supersaturations of 0.11 and $0.73 \%$. Martin et al. (2011) give further details on the quality of the data. Near-surface air temperatures were ob- served to be near $-4{ }^{\circ} \mathrm{C}$, falling to $-13{ }^{\circ} \mathrm{C}$ after the break in cloud.

Figure 1 shows cloud properties, surface radiation, and aerosol concentrations derived from observations. Net surface LW radiation is defined to be positive downwards (absorption by the surface) throughout this paper. The LWC and IWC were derived from measurements using a microwave radiometer, $35 \mathrm{GHz}$ millimetre cloud radar, vertical temperature profiles from radiosondes, and ceilometers, as detailed in Shupe et al. (2013). The methodology is described further in Shupe et al. (2015). The observed liquid water path (LWP) has a reported root mean square error of $25 \mathrm{~g} \mathrm{~m}^{-2}$ (Westwater et al., 2001) and the uncertainty in the observed ice water path (IWP) could be up to a factor of 2 (Birch et al., 2012).

For ease of comparison with the model results, we designate the period from 21:00 UTC on 30 August to 12:00 UTC on 31 August as the "cloudy" period and the period from 00:00 to 06:00 UTC on 1 September as the "nearly cloudfree" period. There is a clear transition in every variable shown in Fig. 1 between these two periods: the liquid and frozen parts of the cloud both descend towards the surface, and the liquid and ice water contents both decrease, causing an increase in the LW emission from the surface. These changes are coincident with a decrease in the observed surface concentrations of aerosol particles larger than $50 \mathrm{~nm}$ (N50) from $>10$ to $<1 \mathrm{~cm}^{-3}$. Total aerosol concentrations as measured by a twin differential mobility particle sizer with a lower detection limit of $3 \mathrm{~nm}$ fell generally below $10 \mathrm{~cm}^{-3}$, with a median value of $2 \mathrm{~cm}^{-3}$ during the nearly cloud-free period. Further details on the quality and data processing of ship-based aerosol measurements are available in Heintzenberg and Leck (2012). CCN concentrations measured at supersaturations as high as $0.73 \%$ during this period were also below $1 \mathrm{~cm}^{-3}$. Additionally, helicopter profiles of aerosol number concentrations were performed from 19:53 to 20:13 UTC on 31 August and from 07:32 to 07:55 UTC on 1 September using a condensation particle counter (Kupiszewski et al., 2013). These indicate that the number concentrations of aerosol larger than $14 \mathrm{~nm}$ were generally below $10 \mathrm{~cm}^{-3}$ up to $850 \mathrm{~m}$ of altitude during the 31 August profile and up to $500 \mathrm{~m}$ of altitude during the 1 September profile. With reference to Fig. 1, we note that these heights are similar to the locations of the observed cloud-top heights at these time periods, and these altitudes were also similar to temperature inversion base heights observed via a scanning microwave radiometer (Kupiszewski et al., 2013).

In-cloud measurements were not performed due to aircraft icing concerns (Tjernström et al., 2014). Additionally, CloudSat+Cloud-Aerosol Lidar with Orthogonal Polarization (CALIOP) cloud retrievals are not available north of $82^{\circ} \mathrm{N}$ and are therefore unavailable for this case (Kay and Gettelman, 2009). Moderate Resolution Imaging Spectroradiometer (MODIS) retrievals have been shown to underestimate cloud cover in the Arctic, particularly over sea ice 

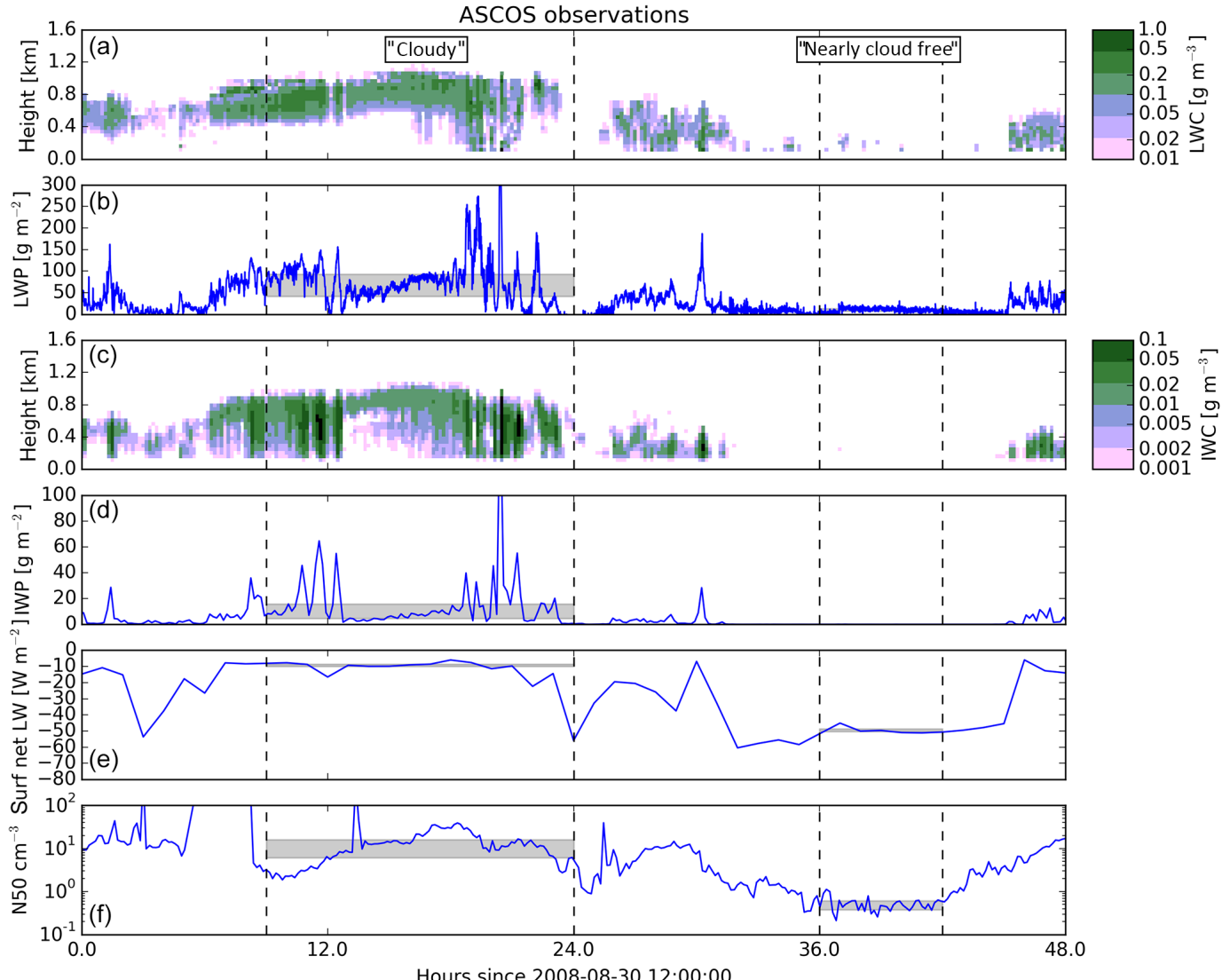

Figure 1. Observed cloud properties, surface radiation, and aerosol concentrations. (a) Liquid water content, (b) liquid water path, (c) ice water content, (d) ice water path, (e) surface net longwave flux, and (f) concentrations of N50. Shaded rectangles indicate the interquartile ranges of LWP, IWP, surface net LW radiation, and N50 during the cloudy and nearly cloud-free periods defined in Sect. 2. Dashed vertical lines indicate the beginnings and endings of these periods.

and for cloud-top heights less than $2 \mathrm{~km}$ (Chan and Comiso, 2013). We therefore consider MODIS-derived cloud information unreliable for this case. Therefore, no reliable observations of cloud droplet number concentrations are available for this case.

As mentioned above, previous analysis (Birch et al., 2012; Mauritsen et al., 2011) has identified these clouds as existing within the tenuous cloud regime: cloud LWC is limited by the availability of aerosol to act as $\mathrm{CCN}$. The hypothesis is that at extremely low $\mathrm{CCN}$ concentrations, each available $\mathrm{CCN}$ is activated, grows through condensation to drizzle droplet sizes, and is removed by sedimentation. It is implicit in this hypothesis that in-cloud precipitation occurs predominantly through liquid-phase processes, although frozenphase processes could contribute to precipitation formation, and glaciation would be an alternate cause of cloud dissipation. In the following sections the aerosol and meteorological environment will be decoupled via sensitivity tests to assess the validity of this hypothesis.

\section{Description of participating models}

Simulations were performed using three large eddy simulation (LES) models and three numerical weather prediction (NWP) models. LES models are fine-resolution models (horizontally several metres to hundreds of metres) with domains typically from hundreds of metres to hundreds of kilometres capable of resolving turbulent eddies and useful for detailed studies of clouds. NWP models are generally coarserresolution (horizontally hundreds of metres to tens of kilometres) models with larger domains (tens of kilometres to global) capable of simulating mesoscale weather systems and performing operational forecasting. The NWP models used in this study all prognose surface temperatures and surface sensible and latent heat fluxes, but these values are prescribed for the LES models in this study. The NWP models can describe the full meteorological variability and can therefore help to separate meteorological versus aerosol effects.

The LES models participating in this study are the University of California, Los Angeles LES with Sectional Aerosol module for Large Scale Applications (UCLALES-SALSA; 
Tonttila et al., 2017), the MISU MIT Cloud and Aerosol LES model (MIMICA; Savre et al., 2014), and the Consortium for Small-scale Modeling (COSMO) model configured as an LES model (Loewe et al., 2017) (hereafter referred to as COSMO-LES). The NWP models are v3.6.1 of the Polar Weather Research and Forecasting model (Polar WRF; Hines et al., 2015), the Met Office Unified Model with Cloud AeroSol Interacting Microphysics (UM-CASIM; Grosvenor et al., 2017), and COSMO configured as an NWP model (Steppeler et al., 2003) (hereafter referred to as COSMONWP). Each of the models is described in detail in previous publications, so we will restrict ourselves to a brief overview here. The participating models are described and compared in Table 1.

UCLALES-SALSA is a combination of an LES model (UCLALES; Stevens et al., 1999; Stevens et al., 2005) and a sectional aerosol and cloud microphysics module (SALSA; Kokkola et al., 2008). A detailed description of UCLALESSALSA can be found in Tonttila et al. (2017). A comparison of UCLALES-SALSA results against those of a previous model intercomparison based on the second Dynamics and Chemistry of Marine Stratocumulus Field Study (DYCOMSII) can also be found in Tonttila et al. (2017). The properties and microphysical processes of aerosol, cloud droplets, and rain are defined for certain size sections (bins). In the current set-up, aerosol has 10 size bins based on dry particle size and cloud droplets have 7 bins that are parallel with the 7 largest aerosol bins. Raindrops have seven size bins which are based on droplet size. Microphysics includes water vapour condensation and evaporation, cloud activation, rain formation, coagulation, and deposition. With the exception of rain formation, these processes are modelled based on physical equations. Rain formation is based on an autoconversion scheme in which a log-normal size distribution $(\sigma=1.1)$ is expected for each cloud bin and droplets larger than $50 \mu \mathrm{m}$ are moved to the first precipitation bin. Subgridscale turbulence is based on the Smagorinsky-Lilly model as described in Seifert et al. (2010). Radiation transfer is calculated following the four-stream radiative transfer solver of $\mathrm{Fu}$ and Liou (1993).

MIMICA is an LES model which uses a two-moment bulk microphysics scheme with five hydrometeor categories (cloud droplets, raindrops, ice crystals, graupel, and snow). MIMICA also includes a two-moment aerosol module providing the possibility to represent different aerosol populations covering a range of size intervals and compositions (Ekman et al., 2006). The autoconversion parameterization and the interactions between liquid particles follow the scheme of Seifert and Beheng (2006). Liquid-ice interactions are parameterized according to the microphysical scheme of Wang and Chang (1993). The subgrid-scale model is based on a Smagorinsky-Lilly eddy diffusivity closure (Lilly, 1992). At the surface, the model uses Monin-Obukhov similarity theory and the momentum fluxes are computed as described in Garratt (1994). The CCN activation is described by the kappa-Köhler theory (Petters and Kreidenweis, 2007). A four-stream radiative transfer solver (Fu and Liou, 1993) is used in the model. A thorough description of MIMICA is given in Savre et al. (2014). The MIMICA model has participated in the ISDAC model intercomparison study (Ovchinnikov et al., 2014) and has also been used to simulate the DYCOMSII case (Savre et al., 2014); in both cases it compared well with other models.

Both COSMO-LES and COSMO-NWP use the twomoment cloud microphysics scheme described in Seifert and Beheng (2006). A fixed log-normal aerosol mode was implemented into COSMO-LES and prognostic aerosol transport, activation, and resuspension following hydrometeor evaporation were implemented in COSMO-NWP following Possner et al. (2017). Aerosol activation to cloud droplets is performed following the scheme described in Nenes and Seinfeld (2003) and Fountoukis and Nenes (2005). The twostream radiation scheme after Ritter and Geleyn (1992) calculates the radiation transfer in COSMO. The boundary layer turbulence is parameterized using a 3-D scheme in COSMOLES (Herzog et al., 2002a, b) and a 1-D vertical turbulent diffusion scheme based on Mellor and Yamada (1974) in COSMO-NWP. The minimum threshold for the eddy diffusivity in COSMO-NWP was adjusted to $0.01 \mathrm{~m}^{2} \mathrm{~s}^{-1}$ (Possner et al., 2014). The COSMO model participated in the ISDAC LES model intercomparison study (Ovchinnikov et al., 2014), and the predicted IWP and LWP were within the range of the other models.

The physics options used in the Polar WRF simulations are based on the recommendations described in Hines et al. (2015). Cloud microphysical processes are parameterized according to the double-moment scheme of Morrison et al. (2005a). Autoconversion of cloud droplets to rain is treated according to the scheme of Seifert and Beheng (2006). For droplet activation in the CCN30fixed and CCN80fixed cases (see Sect. 4), the scheme of Abdul-Razzak and Ghan (2000) is used assuming a fixed background concentration of CCN. There is no prognostic treatment of aerosols in the WRF simulations. The atmospheric boundary layer is represented by the Mellor-Yamada-Nakanishi-Niino (MYNN) scheme (Nakanishi and Niino, 2006), and the rapid radiative transfer model (RRTMG; Clough et al., 2005) is used for both longwave and shortwave radiation.

The UM-CASIM model has been described previously in Grosvenor et al. (2017) and Miltenberger et al. (2018). However, the subgrid cloud scheme described in Grosvenor et al. (2017) was not used for this study. Boundary layer processes, including surface fluxes of moisture and heat, are parameterized with the blended boundary layer scheme (Lock et al., $2000,2015)$ and subgrid-scale turbulent processes are represented with a 3-D Smagorinsky-type turbulence scheme (Halliwell, 2014; Stratton et al., 2015). A two-stream radiation scheme is used, as described in Manners et al. (2016). It is possible to run the UM-CASIM model as a fully coupled atmosphere-ocean model, but for this study a fixed sea-ice 
Table 1. Description of models participating in this study.

\begin{tabular}{|c|c|c|c|c|c|c|}
\hline & $\begin{array}{l}\text { UCLALES- } \\
\text { SALSA }\end{array}$ & MIMICA & COSMO-LES & COSMO-NWP & WRF & UM-CASIM \\
\hline $\begin{array}{l}\text { Described } \\
\text { in }\end{array}$ & $\begin{array}{l}\text { Tonttila et al. } \\
\text { (2017) }\end{array}$ & $\begin{array}{l}\text { Savre et al. } \\
(2014)\end{array}$ & $\begin{array}{l}\text { Loewe et al. } \\
(2017) \text {, Seifert } \\
\text { and Beheng } \\
(2006) \text {, Vogel } \\
\text { et al. (2009) }\end{array}$ & $\begin{array}{l}\text { Steppeler et al. } \\
\text { (2003), Seifert } \\
\text { and Beheng } \\
(2006) \text {, Vogel } \\
\text { et al. (2009) }\end{array}$ & $\begin{array}{l}\text { Hines et al. } \\
(2015)\end{array}$ & $\begin{array}{l}\text { Grosvenor et al. } \\
\text { (2017) }\end{array}$ \\
\hline $\begin{array}{l}\text { Condition } \\
\text { for ice } \\
\text { nucleation }\end{array}$ & $\begin{array}{l}\text { No ice nucle- } \\
\text { ation }\end{array}$ & $\begin{array}{l}S_{\mathrm{i}}>0.05 \text { and } \\
q_{\mathrm{c}}> \\
0.001 \mathrm{~g} \mathrm{~kg}^{-1}\end{array}$ & $\begin{array}{l}S_{\mathrm{i}}>0.05 \text { and } \\
q_{\mathrm{c}}> \\
0.001 \mathrm{~g} \mathrm{~kg}^{-1}\end{array}$ & $\begin{array}{l}S_{\mathrm{i}}>0.05 \text { and } \\
q_{\mathrm{c}}> \\
0.001 \mathrm{~g} \mathrm{~kg}^{-1}\end{array}$ & $\begin{array}{l}S_{1}>-0.001 \\
\text { and } T<-8^{\circ} \mathrm{C}\end{array}$ & $\begin{array}{l}S_{1}>-0.001 \\
\text { and } T<-8^{\circ} \mathrm{C}\end{array}$ \\
\hline $\begin{array}{l}\text { Number of } \\
\text { vertical lev- } \\
\text { els below } \\
2 \mathrm{~km}\end{array}$ & 112 & 128 & 124 & 17 & 25 & 24 \\
\hline $\begin{array}{l}\text { Finest ver- } \\
\text { tical resolu- } \\
\text { tion }(\mathrm{m})\end{array}$ & 15.0 & 7.5 & 7.5 & 24.2 & 30.2 & 10.8 \\
\hline $\begin{array}{l}\text { Coarsest } \\
\text { vertical } \\
\text { resolution } \\
\text { below } 2 \mathrm{~km} \\
\text { (m) }\end{array}$ & 47.2 & 47.7 & 228.3 & 237.1 & 141.9 & 156.7 \\
\hline $\begin{array}{l}\text { Coarsest } \\
\text { vertical } \\
\text { resolution } \\
\text { below } \\
1.5 \mathrm{~km} \mathrm{(m)}\end{array}$ & 23.8 & 35.6 & 35.6 & 202.3 & 108.8 & 136.7 \\
\hline $\begin{array}{l}\text { Horizontal } \\
\text { resolution }\end{array}$ & $50 \mathrm{~m}$ & $62.5 \mathrm{~m}$ & $100 \mathrm{~m}$ & $1 \mathrm{~km}$ & $1 \mathrm{~km}$ & $1 \mathrm{~km}$ \\
\hline $\begin{array}{l}\text { Horizontal } \\
\text { domain } \\
\text { size }\end{array}$ & $3.15 \mathrm{~km}$ & $6 \mathrm{~km}$ & $6.4 \mathrm{~km}$ & $600 \mathrm{~km}$ & $600 \mathrm{~km}$ & $600 \mathrm{~km}$ \\
\hline $\begin{array}{l}\text { Prognostic } \\
\text { aerosol* }\end{array}$ & $\begin{array}{l}\text { Sectional } \\
\text { aerosol }(10 \\
\text { size bins; dry } \\
\text { diameter from } \\
3 \mathrm{~nm} \text { to } 1 \mu \mathrm{m})\end{array}$ & $\begin{array}{l}\text { Two-moment } \\
\text { bulk (Igel et al., } \\
2017 \text { ) }\end{array}$ & None & None & None & $\begin{array}{l}\text { Two-moment } \\
\text { bulk }\end{array}$ \\
\hline
\end{tabular}

* Only used in CCN30prog and CCN80prog simulations; described in Sect. 4.

fraction of $100 \%$ and a fixed sea-ice thickness of $2 \mathrm{~m}$ were used. Activation of cloud droplets in simulations without prescribed CDNCs is performed following the scheme described in Abdul-Razzak et al. (1998) and Abdul-Razzak and Ghan (2000).

Except UCLALES-SALSA and WRF, all models in this study contained five hydrometeor classes: cloud droplets, rain, cloud ice crystals, snow, and graupel. These hydrometeor classes are represented as gamma distributions with prescribed shape parameters and prognosed bulk mass and number concentrations. WRF contains the hydrometeor classes described above except graupel. UCLALES-SALSA represents cloud droplets and raindrops using seven sectional size bins for each species, tracking number and mass independently. Frozen water species are not currently simulated by
UCLALES-SALSA. Sedimentation of cloud droplets is simulated only by UCLALES-SALSA, WRF, and UM-CASIM.

Nucleation of cloud ice was conditionally permitted in each model within a defined range of temperatures $(T)$, cloud droplet mass mixing ratios $\left(q_{\mathrm{c}}\right)$, liquid supersaturations $\left(S_{1}\right)$, and ice supersaturations $\left(S_{\mathrm{i}}\right)$. In MIMICA and the two COSMO models, ice forms in the presence of supercooled liquid water $\left(S_{\mathrm{i}}>0.05\right.$ and $q_{\mathrm{c}}>0.002$ or $0.001 \mathrm{~g} \mathrm{~kg}^{-1}$, respectively) and for WRF and UM-CASIM ice forms at $T<$ $-8^{\circ} \mathrm{C}$ in the presence of supercooled liquid water. These differences will have minimal impact on the simulation, as cloud-top temperatures are generally below $-8^{\circ} \mathrm{C}$.

For all models and all simulations, the rate of ice nucleation was parameterized following Fridlind et al. (2012) and Morrison et al. (2011). The change in ICNC due to nucle- 
ation of cloud ice in each time step was therefore

$\Delta \mathrm{ICNC}=\max \left(0, \mathrm{ICNC}_{\text {fixed }}-\mathrm{ICNC}\right)$,

where ICNC is the cloud ice crystal number concentration, $\triangle \mathrm{ICNC}$ is the change in ICNC due to ice nucleation during a single model time step, and $\mathrm{ICNC}_{\text {fixed }}$ is a chosen fixed value dependent on the experiment: $1,0.2$, or $0.02 \mathrm{~L}^{-1}$ for experiments labelled ICNC1p00, ICNC0p20, or ICNC0p02, respectively (see Sect. 4). Thus, whenever the conditions for ice formation are met, any loss in $N_{\text {ice }}$ due to sedimentation, autoconversion to snow, or scavenging will be exactly compensated for by further activation to maintain the ICNC as $\mathrm{ICNC}_{\text {fixed }}$. For simulations labelled NOICE, the models were run without any formation of frozen cloud water permitted.

\section{Description of simulations}

For the UM-CASIM simulations, a global simulation initialized using the European Centre for Medium-Range Weather Forecasts (ECMWF) global analysis was performed to produce a set of time-varying boundary conditions. The WRF and COSMO-NWP models used boundary conditions directly from the ECMWF global analysis. The three NWP models were then run with a $0.009^{\circ} \times 0.009^{\circ}$ horizontal resolution rotated grid (approximately $1 \times 1 \mathrm{~km}$ throughout the domain) spanning a $600 \times 600 \mathrm{~km}$ domain centred at $87.3^{\circ} \mathrm{N}, 6.0^{\circ} \mathrm{W}$. The period of interest for this study is the transition period of the observed cloud from the cloudy state to the nearly cloud-free state, starting approximately at 12:00 UTC on 31 August (see Sect. 2 above). The NWP models were therefore started at 12:00 UTC on 30 August 2008 to allow for $24 \mathrm{~h}$ to reach a representative state, and the total simulation duration was $48 \mathrm{~h}$.

Initial profiles of potential temperature, humidity, and wind speed for the LES models were taken from the $31 \mathrm{Au}-$ gust 05:35 UTC radiosonde observations from the ASCOS campaign (Fig. 2). No flux of heat and moisture from or to the surface was permitted due to the sea-ice cover. Sensible and latent heat fluxes at the surface were $<1 \mathrm{~W} \mathrm{~m}^{-2}$ in the UMCASIM modelling results, and observed surface fluxes were generally $<5 \mathrm{~W} \mathrm{~m}^{-2}$ during the ASCOS campaign (Tjernström et al., 2012; Sedlar et al., 2011). Surface temperatures were prescribed to be $-1.8^{\circ} \mathrm{C}$. Furthermore, the set-up of all LES models follows the large-scale subsidence description of Ovchinnikov et al. (2014), with divergence assumed to be constant below a height of $2 \mathrm{~km}$. The value of the divergence was chosen to be $1.5 \times 10^{-6} \mathrm{~s}^{-1}$. Preliminary simulations with UCLALES-SALSA showed that a divergence of $1.5 \times 10^{-6} \mathrm{~s}^{-1}$ was too low in this model to balance radiative cooling and the associated mixing, and the cloud layer would continuously rise at a rate similar to the clouds in the COSMO-LES CDNC30 simulations (e.g. Fig. 3). The increased length of the UCLALES-SALSA simulations compared to the COSMO-LES simulations (discussed next para- graph) allows the cloud layer to rise to unrealistic altitudes. A larger value of $5 \times 10^{-6} \mathrm{~s}^{-1}$ was therefore used instead for the subsidence in the UCLALES-SALSA simulations. While we do not investigate sensitivities to prescribed subsidence in this study, other studies have shown that differences in prescribed subsidence affect Arctic mixed-phase cloud LWP and IWP (Young et al., 2018). Within UCLALES-SALSA, subsidence only affects the tendencies of temperature and water vapour and does not directly alter advection of air parcels, aerosols, cloud droplets or rain.

Due to numerical instabilities, the COSMO-LES simulations are restricted to a duration of $16 \mathrm{~h}$, including $2 \mathrm{~h}$ of spin-up during which ice formation is not permitted. These instabilities are visible in the full model results as waves in the upper atmosphere. These waves do not reach the boundary layer during the simulations, and thus they do not influence the cloud in the boundary layer. In order to focus on the transition period starting approximately at 12:00 UTC on 31 August, the COSMO-LES simulations were therefore started at 06:00 UTC, 31 August. UCLALES-SALSA simulations were run from 00:00 UTC on 31 August for $36 \mathrm{~h}$, including $3 \mathrm{~h}$ of spin-up, during which coagulation, sedimentation, and autoconversion are disabled. MIMICA simulations were run from 12:00 UTC, 30 August for $72 \mathrm{~h}$, including $2 \mathrm{~h}$ of spinup, but we only show results from the first $48 \mathrm{~h}$ in this study. As we have not prescribed any time-varying surface fluxes or large-scale forcings for the LES models and the diurnal cycles in this case are weak, the LES model results are largely independent of the start time for this case.

Several sensitivity experiments with different treatments and concentrations of CCN and ICNC were carried out (Table 2). The values chosen for the sensitivity studies were based on observations of aerosol concentrations during the ASCOS campaign. First, to make the models as similar as possible, we performed simulations with prescribed CDNCs. We first prescribed a CDNC of $30 \mathrm{~cm}^{-3}$ (CDNC30), as mean $\mathrm{CCN}$ concentrations at a supersaturation of $0.2 \%$ were observed to be $26.55 \mathrm{~cm}^{-3}$ over the ice drift period (Martin et al., 2011). Then, in order to test the sensitivity to reduced aerosol concentrations, we perform simulations with the $\mathrm{CDNC}$ reduced to $3 \mathrm{~cm}^{-3}$ (CDNC03).

We then performed simulations in which cloud droplet activation was calculated based on an aerosol size distribution. We represented the aerosol size distribution using the lognormal fit of Igel et al. (2017). A single log-normal mode was fit to observations of accumulation-mode particles made on-board the icebreaker Oden using a twin differential mobility particle sizer with an inlet height around 20-25 m above the surface (Leck et al., 2001). Further details on the quality and data processing of ship-based aerosol measurements are available in Heintzenberg and Leck (2012). This yielded a median diameter of $94 \mathrm{~nm}$ and a geometric standard deviation of 1.5. For simplicity, we assume that the aerosol particles are composed entirely of ammonium sulfate, but in reality $43 \%$ of the non-refractory aerosol mass was observed 

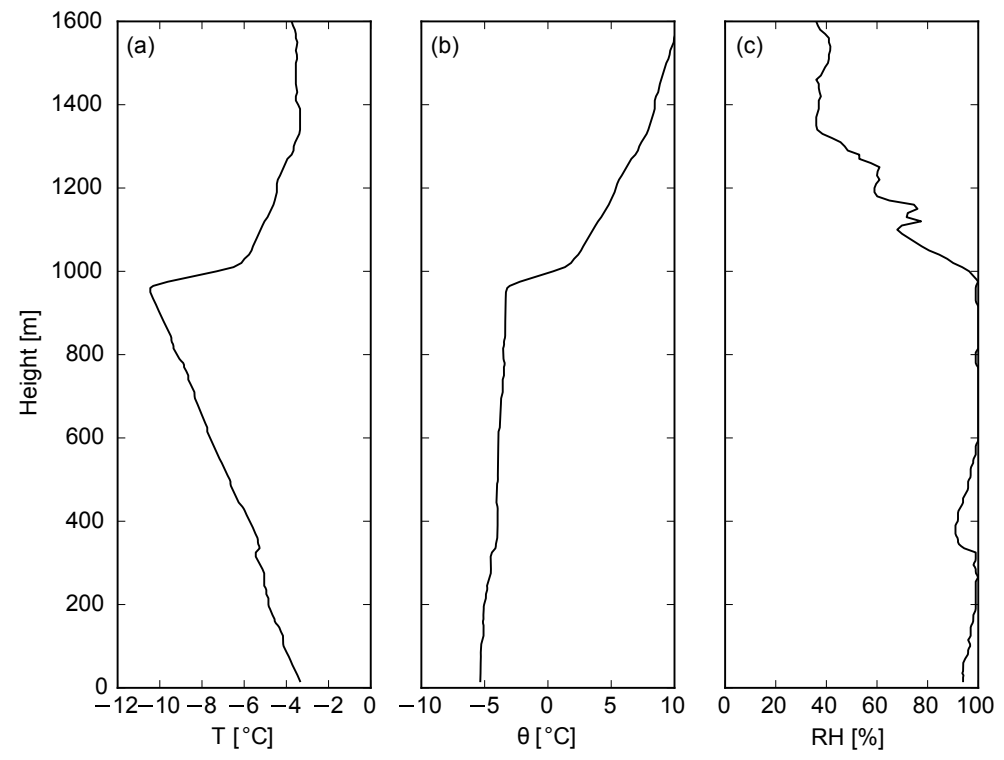

Figure 2. 31 August 05:35 UTC radiosonde observations of (a) absolute temperature, (b) potential temperature, and (c) relative humidity from the ASCOS campaign.

Table 2. Description of simulations performed. The last six columns indicate which models performed simulations of each case. UCL: UCLALES-SALSA, MIM: MIMICA, COL: COSMO-LES, CON: COSMO-NWP, UMC: UM-CASIM.

\begin{tabular}{|c|c|c|c|c|c|c|c|c|c|c|}
\hline Name & $\begin{array}{l}\text { Initial CCN } \\
\left(\mathrm{cm}^{-3}\right)\end{array}$ & $\begin{array}{l}\text { Prognostic } \\
\text { aerosol }\end{array}$ & $\begin{array}{l}\mathrm{CDNC} \\
\left(\mathrm{cm}^{-3}\right)\end{array}$ & $\begin{array}{l}\text { ICNC } \\
\left(\mathrm{L}^{-1}\right)\end{array}$ & UCL & MIM & $\mathrm{COL}$ & $\mathrm{CON}$ & WRF & UMC \\
\hline CDNC30_NOICE & none & no & 30 & 0.00 & & $\checkmark$ & $\checkmark$ & $\checkmark$ & $\checkmark$ & $\checkmark$ \\
\hline CDNC03_NOICE & none & no & 3 & 0.00 & & $\checkmark$ & $\checkmark$ & $\checkmark$ & $\checkmark$ & $\checkmark$ \\
\hline CDNC30_ICNCOp02 & none & no & 30 & 0.02 & & $\checkmark$ & $\checkmark$ & & $\checkmark$ & $\checkmark$ \\
\hline CDNC03_ICNCOp02 & none & no & 3 & 0.02 & & $\checkmark$ & $\checkmark$ & & $\checkmark$ & $\checkmark$ \\
\hline CDNC30_ICNCOp20 & none & no & 30 & 0.20 & & $\checkmark$ & $\checkmark$ & $\checkmark$ & $\checkmark$ & $\checkmark$ \\
\hline CDNC03_ICNCOp20 & none & no & 3 & 0.20 & & $\checkmark$ & $\checkmark$ & $\checkmark$ & $\checkmark$ & $\checkmark$ \\
\hline CDNC30_ICNC1p00 & none & no & 30 & 1.00 & & $\checkmark$ & $\checkmark$ & $\checkmark$ & $\checkmark$ & $\checkmark$ \\
\hline CDNC03_ICNC1p00 & none & no & 3 & 1.00 & & $\checkmark$ & $\checkmark$ & $\checkmark$ & $\checkmark$ & $\checkmark$ \\
\hline CCN30fixed_NOICE & 30 & no & prognostic & 0.00 & & $\checkmark$ & $\checkmark$ & $\checkmark$ & $\checkmark$ & $\checkmark$ \\
\hline CCN80fixed_NOICE & 80 & no & prognostic & 0.00 & & $\checkmark$ & $\checkmark$ & $\checkmark$ & $\checkmark$ & $\checkmark$ \\
\hline CCN30fixed_ICNCOp02 & 30 & no & prognostic & 0.02 & & $\checkmark$ & $\checkmark$ & & $\checkmark$ & $\checkmark$ \\
\hline CCN80fixed_ICNCOp02 & 80 & no & prognostic & 0.02 & & $\checkmark$ & $\checkmark$ & & $\checkmark$ & $\checkmark$ \\
\hline CCN30fixed_ICNCOp20 & 30 & no & prognostic & 0.20 & & $\checkmark$ & $\checkmark$ & $\checkmark$ & $\checkmark$ & $\checkmark$ \\
\hline CCN80fixed_ICNCOp20 & 80 & no & prognostic & 0.20 & & $\checkmark$ & $\checkmark$ & $\checkmark$ & $\checkmark$ & $\checkmark$ \\
\hline CCN03prog_NOICE & 3 & yes & prognostic & 0.00 & $\checkmark$ & $\checkmark$ & & $\checkmark$ & & $\checkmark$ \\
\hline CCN30prog_NOICE & 30 & yes & prognostic & 0.00 & $\checkmark$ & $\checkmark$ & & $\checkmark$ & & $\checkmark$ \\
\hline CCN80prog_NOICE & 80 & yes & prognostic & 0.00 & $\checkmark$ & $\checkmark$ & & $\checkmark$ & & $\checkmark$ \\
\hline CCN03prog_ICNCOp02 & 3 & yes & prognostic & 0.02 & & $\checkmark$ & & & & $\checkmark$ \\
\hline CCN30prog_ICNCOp02 & 30 & yes & prognostic & 0.02 & & $\checkmark$ & & & & $\checkmark$ \\
\hline CCN80prog_ICNCOp02 & 80 & yes & prognostic & 0.02 & & $\checkmark$ & & & & $\checkmark$ \\
\hline CCN03prog_ICNCOp20 & 3 & yes & prognostic & 0.20 & & $\checkmark$ & & $\checkmark$ & & $\checkmark$ \\
\hline CCN30prog_ICNCOp20 & 30 & yes & prognostic & 0.20 & & $\checkmark$ & & $\checkmark$ & & $\checkmark$ \\
\hline CCN80prog_ICNC0p20 & 80 & yes & prognostic & 0.20 & & $\checkmark$ & & $\checkmark$ & & $\checkmark$ \\
\hline
\end{tabular}

to be organic (Chang et al., 2011) with low hygroscopicity (Leck and Svensson, 2015). We initially chose an aerosol number concentration of $30 \mathrm{~cm}^{-3}$ (CCN30) to represent the cloudy period based on the observed $\mathrm{CCN}$ concentrations.
However, preliminary simulations with UCLALES-SALSA indicated that an initial $\mathrm{CCN}$ concentration of $30 \mathrm{~cm}^{-3}$ would result in the dissipation of the cloud (as will be shown in Sect. 5.4), so a larger value of $80 \mathrm{~cm}^{-3}$ (CCN80) was cho- 
sen as a sensitivity study. Additionally, we chose a value of $3 \mathrm{~cm}^{-3}$ to test the sensitivity of our results to further reductions in the $\mathrm{CCN}$ concentration. In order to assess the sensitivity to the removal of aerosol by cloud processes within the models, we perform simulations with either constant aerosol or with prognostic aerosol processing. In the CCN30fixed and CCN80fixed cases, the aerosol concentration remains constant in space and time and is not affected by cloud processes. Cloud droplet activation occurs only if the number of newly activated cloud droplets exceeds the current number of cloud droplets in a given grid cell, in which case the CDNC is updated to the number calculated by the activation parameterization. In the prognostic aerosol simulations (CCN03prog, CCN30prog and CCN80prog), aerosol is removed through activation into cloud droplets, resuspended upon evaporation, and transported by advection.

In addition to the sensitivity to $\mathrm{CCN}$, we also investigated the sensitivity of the clouds within the models to ICNC. Observations of ice-nucleating particles (INPs) are not available for this period, as the concentrations at the surface were below the detection limit of the instrument (Loewe et al., 2017). Following Loewe et al. (2017), we chose a prescribed ICNC of $0.2 \mathrm{~L}^{-1}$ as our control simulation (ICNC0p20) based on previous observations of INP in the Arctic from AOE-91 and AOE-96 (Bigg, 1996; Bigg and Leck, 2001). Additionally, we performed a liquid-phase-only sensitivity study with no ice nucleation (NOICE) and additional sensitivity studies with prescribed ICNCs of 0.02 (ICNCOp02) and $1 \mathrm{~L}^{-1}$ (ICNC1p00).

\section{Liquid-phase-only simulations}

\subsection{Base case: $\mathrm{CDNC} 30 \mathrm{~cm}^{-3}$}

We begin by discussing the CDNC30_NOICE case. Figure 3 shows the LWCs and the mass mixing ratios of cloud droplets and rain predicted by the MIMICA, COSMO-LES, COSMONWP, WRF, and UM-CASIM models. Results in this figure and throughout the paper are shown at the centre of the domain for all models. We note that the direct comparison of results between LES and NWP models is not trivial: the LES models in this study used wrapped boundary conditions and time-invariant surface fluxes and therefore would always be expected to tend towards some equilibrium cloud state. The NWP models, however, simulate the advection of different air masses with different histories through the domain, and changes due to differences in air masses can be conflated with the temporal evolution of a single cloud system. With these challenges in mind, we note that the surface is homogeneously covered in sea ice in all models, and we expect that the centre of the domain will be representative for our case study. In order to assess this, we show statistics from the NWP models over a $100 \mathrm{~km}^{2}$ area in the centre of the domain in the Supplement (Figs. S1-S3). Figure S1 shows character- istics of the distribution of LWP and IWP within the specified $100 \mathrm{~km}^{2}$ area as simulated by the three NWP models for the CDNC30_ICNC0p20 case. Figures S2 and S3 show statistics of LWP, IWP, and net surface longwave radiation for the NWP models for all of the sensitivity studies. We note that the centre-of-domain values are nearly always within the interquartile range of the $100 \mathrm{~km}^{2}$ area values. Furthermore, centre-of-domain values are sufficiently close to the domain medians and have similar enough responses to changes in CDNC, CCN, and ICNC as not to change the conclusions of our study. We expect less spatial variability in the LES models than the NWP models, which were run with periodic boundary conditions and fixed surface fluxes. Thus, the centre-of-domain points are representative for the domain in both NWP and LES models.

All models produce clouds near $1 \mathrm{~km}$ of altitude. Despite no inclusion of ice processes, the predicted LWC values are generally within a factor of 2 of those observed during the cloudy period. In all models, the cloud droplet mass mixing ratios generally increase with altitude within the cloud. The MIMICA model predicts the thickest cloud (cloud depth $\sim 600 \mathrm{~m}$ ) with the largest cloud droplet mass mixing ratios, reaching values greater than $0.5 \mathrm{~g} \mathrm{~kg}^{-1}$ at cloud top. The cloud depths simulated by WRF and UM-CASIM are slightly thinner $(\sim 500 \mathrm{~m})$, and the cloud droplet mass mixing ratios are smaller $\left(\sim 0.3 \mathrm{~g} \mathrm{~kg}^{-1}\right)$. The cloud depths produced by COSMO-NWP are similar to those produced by WRF and UM-CASIM, but the cloud droplet mass mixing ratios are much smaller $\left(\sim 0.05 \mathrm{~g} \mathrm{~kg}^{-1}\right)$. The cloud-top height predicted by COSMO-NWP is greater than for any other model. This is consistent for all cases in this study simulated by COSMO-NWP. We note that COSMO-NWP has the coarsest vertical resolution of all the models participating in this study. The COSMO-LES model produces the thinnest clouds (cloud depth $\sim 400 \mathrm{~m}$ ) with the lowest cloud droplet mass mixing ratios $\left(<0.2 \mathrm{~g} \mathrm{~kg}^{-1}\right)$. COSMO-LES produces a consistent layer of rain below cloud with mass mixing ratios $\sim 0.04 \mathrm{~g} \mathrm{~kg}^{-1}$. The other four models, however, produce less rain with more variability.

None of the models predict the observed dissolution of the cloud during the second half of the examined period, except perhaps UM-CASIM. We will show in Sect. 6.1 that this is generally true even if cloud ice is included in the models. UM-CASIM predicts thinning of the cloud during the last $6 \mathrm{~h}$ of simulation, suggesting a possible meteorological contribution to dissipation, but the other two NWP models do not predict this thinning. Previous analysis of this case has identified these clouds as existing within the tenuous cloud regime and has suggested that the dissipation of the cloud is related to extremely low $\left(<1 \mathrm{~cm}^{-3}\right)$ observed CCN concentrations. The prescribed CDNC cases would not be expected to reproduce this effect, as the parameterization of the cloud droplet activation is not linked to CCN availability. However, other potential causes of the transition could be resolved by the models. In particular, the NWP models would be expected 

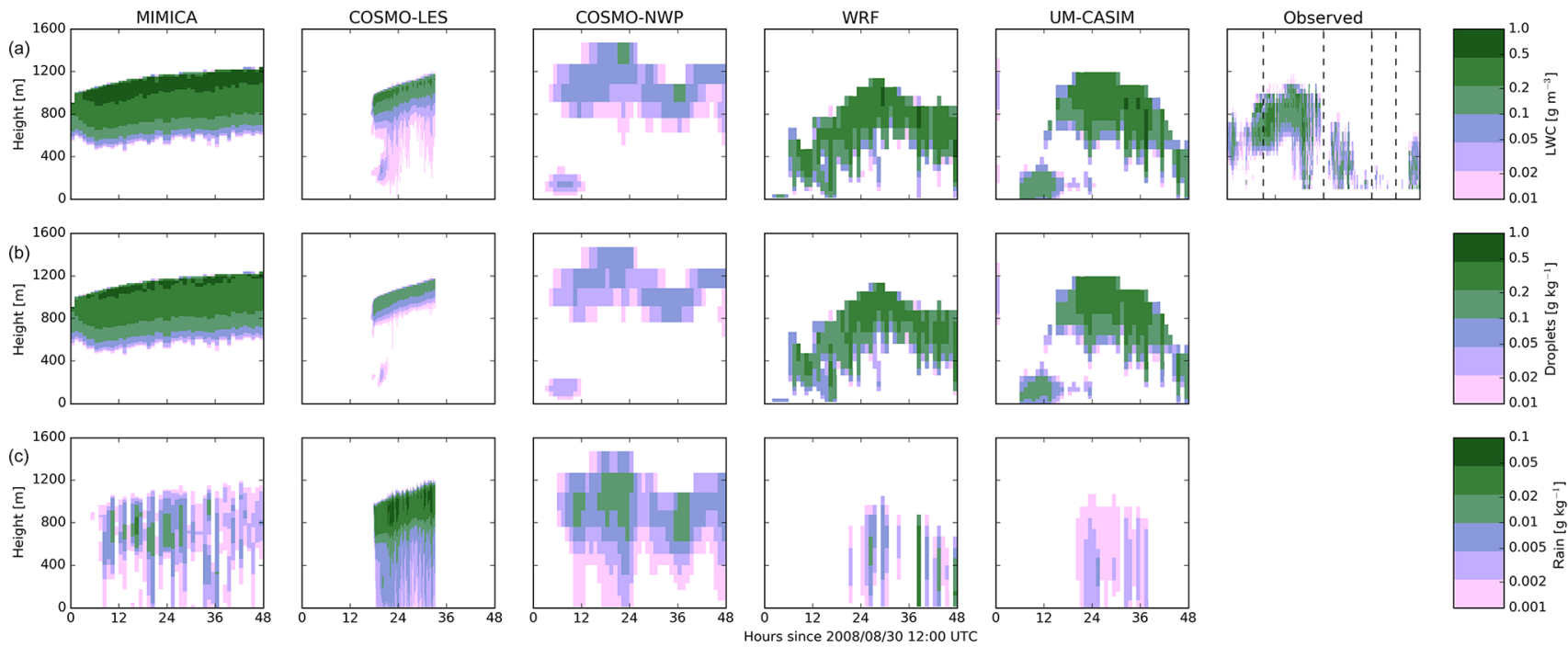

Figure 3. Liquid water content and cloud droplet and rain mass mixing ratios in the simulations with the following: a prescribed CDNC of $30 \mathrm{~cm}^{-3}$ and no cloud ice permitted (CDNC30_NOICE); and liquid water content derived from observations. (a) Liquid water content. (b) Mass mixing ratios of cloud droplets. (c) Mass mixing ratios of rain. Results are shown (from left to right) from the MIMICA, COSMOLES, COSMO-NWP, WRF, and UM-CASIM models. Observed liquid water contents are shown in the rightmost column. Vertical dashed lines indicate the beginnings and endings of the cloudy and nearly cloud-free periods.

to yield more realistic changes in meteorological conditions due to advective transport through changes with time in the boundary conditions applied to these models. However, the vertical atmospheric structure at the interiors of the domains will evolve to be different than at the boundaries. Nevertheless, the absence of this transition in these modelling results supports the interpretation that the LWC of these clouds is CCN limited. We will discuss this further in Sect. 5.2 when we discuss the lower prescribed CDNC case.

In order to explain the differences between the results of the different models, Fig. 4 shows the liquid-phase process rates for this simulation (autoconversion of cloud droplets to rain, sedimentation of cloud droplets, and sedimentation of rain). The larger mass mixing ratios of rain and the thinner cloud predicted by COSMO-LES is due to the larger autoconversion tendencies $\left(>1 \times 10^{-4} \mathrm{~g} \mathrm{~m}^{-3} \mathrm{~s}^{-1}\right.$ vs. $10^{-6}$ to $10^{-5} \mathrm{~g} \mathrm{~m}^{-3} \mathrm{~s}^{-1}$ in other models). Autoconversion rates greater than $2 \times 10^{-6} \mathrm{~g} \mathrm{~m}^{-3} \mathrm{~s}^{-1}$ exist even in regions where the cloud droplet mass concentration is less than $0.01 \mathrm{~g} \mathrm{~cm}^{-3}$, the lower limit of the colour scale shown in Fig. 3. Autoconversion rates and cloud droplet mass mixing ratios both decrease by about 2 orders of magnitude from their maximums near cloud top to the layer between 200 and $700 \mathrm{~m}$.

By dividing the mass of cloud droplets by the autoconversion rates from each model, an autoconversion timescale can be estimated for each model. This autoconversion timescale is less than $1 \mathrm{~h}$ for COSMO-LES, on the order of several hours for COSMO-NWP, approximately 1 day for WRF and UM-CASIM, and several days for MIMICA for this case. The COSMO-LES model also has the greatest tendencies due to rain sedimentation $\left(>10^{-4} \mathrm{~g} \mathrm{~m}^{-3} \mathrm{~s}^{-1}\right)$. These large sedimentation tendencies are partially explained by the fact that COSMO-LES produces a greater mass of rain of all the models for this case. The higher cloud droplet mixing ratios seen in the MIMICA results are due to a combination of lower autoconversion tendencies and a lack of cloud droplet sedimentation in this model.

Figure 5 shows scatter plots of the autoconversion tendencies plotted against the cloud droplet mass mixing ratios in order to allow us to examine this process in more detail. The large differences in autoconversion tendencies are despite the fact that the same autoconversion scheme (Seifert and Beheng, 2006) is used in MIMICA, COSMO-LES, COSMONWP, and WRF. COSMO-LES, COSMO-NWP, and WRF all prescribed the same maximum cloud droplet radius to be used for autoconversion $(40 \mu \mathrm{m})$, and MIMICA used a similar value $(50 \mu \mathrm{m})$. The initial difference in autoconversion tendencies between COSMO-LES and COSMO-NWP can be explained primarily by the difference in cloud droplet mass mixing ratios: as there is more mass of cloud droplets available to form rain in COSMO-LES, autoconversion tendencies are greater. The Seifert and Beheng (2006) autoconversion scheme also predicts greater autoconversion rates if rain constitutes a greater proportion of the liquid water mass within a given grid cell. This results in a positive feedback on any other model differences that affect autoconversion rates, enhancing differences in autoconversion rates between COSMO-LES and COSMO-NWP. Autoconversion tendencies per unit mass of cloud droplets are clearly greater in COSMO-LES and COSMO-NWP than in WRF, MIMICA, 

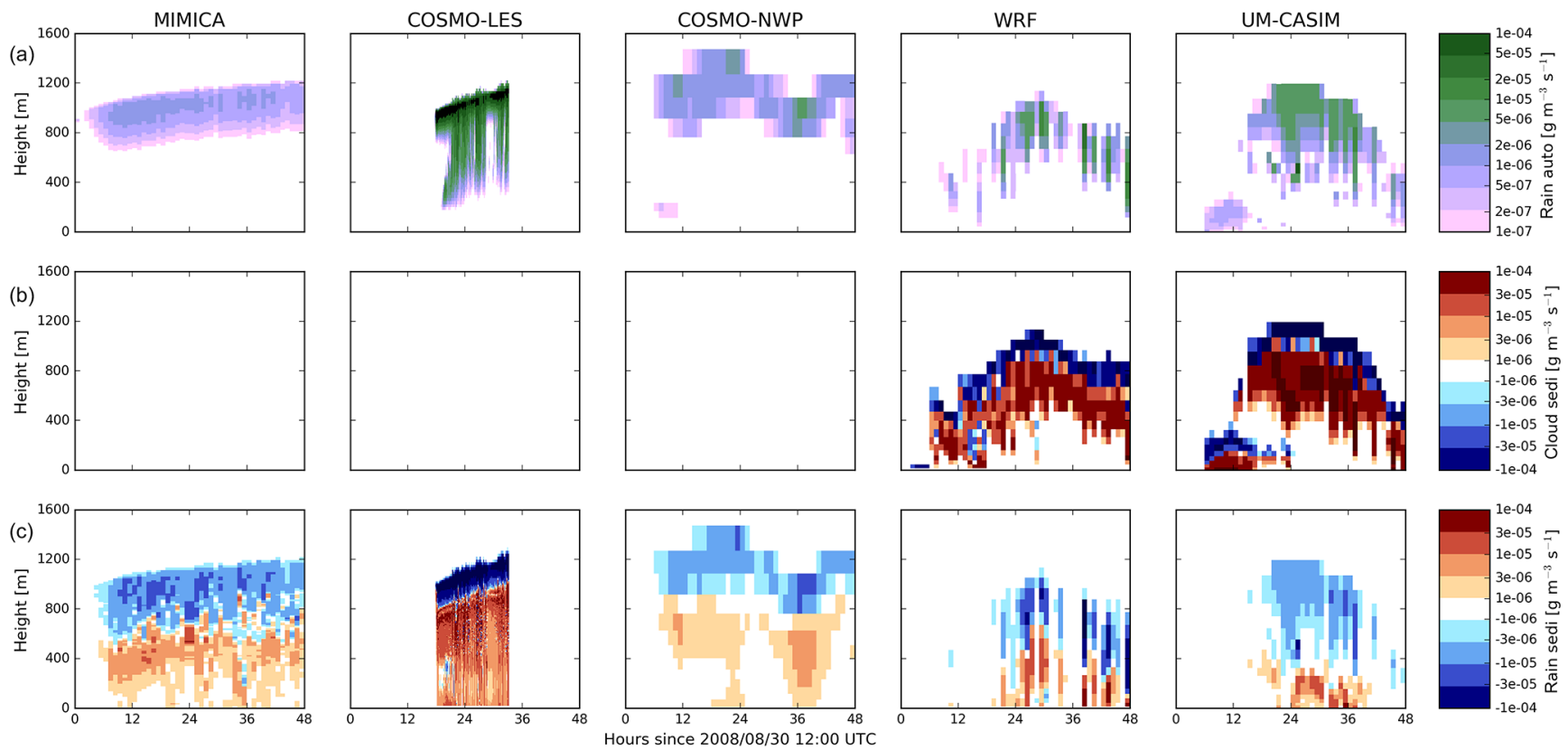

Figure 4. Tendencies of mixing ratios of cloud water and rainwater due to liquid-phase processes for simulations with a prescribed CDNC of $30 \mathrm{~cm}^{-3}$ and no cloud ice permitted (CDNC30_NOICE). (a) Autoconversion of cloud droplets to rain, (b) sedimentation of cloud droplets, and (c) sedimentation of raindrops. Results are shown (from left to right) from the MIMICA, COSMO-LES, COSMO-NWP, WRF, and UM-CASIM models. Note that only WRF and UM-CASIM simulate the sedimentation of cloud droplets.

and UM-CASIM for the CDNC30_NOICE case. As cloud droplet activation is prescribed in this case, autoconversion is similarly treated in all models except for UM-CASIM, and no frozen processes are permitted in this case, we believe that the differences in autoconversion rates per unit cloud droplet mass are due primarily to the differences in the representation of the cloud droplet size distribution. MIMICA, COSMOLES, COSMO-NWP, and WRF represent the cloud droplet size distribution using a gamma distribution defined by

$\frac{\mathrm{d} N}{\mathrm{~d} x}=A x^{\nu_{1}} \exp \left(-\lambda_{1} x^{\mu}\right)$,

where $x$ is the cloud droplet mass, and $\mu$ and $\nu_{1}$ are shape parameters. The intercept and slope parameters $A$ and $\lambda_{1}$ are defined by

$$
\begin{aligned}
& A=\frac{\mu \mathrm{CDNC}}{\Gamma\left(\frac{v_{1}+1}{\mu}\right)} \lambda_{1} \frac{\nu_{1}+1}{\mu}, \\
& \lambda_{1}=\left[\frac{\Gamma\left(\frac{v_{1}+1}{\mu}\right)}{\Gamma\left(\frac{v_{1}+2}{\mu}\right)} \bar{x}\right]^{-\mu},
\end{aligned}
$$

where $\bar{x}$ is the mean cloud droplet mass. However, the prescribed shape parameters are different between the different models: COSMO-LES and COSMO-NWP used shape parameters $\mu=0.33$ and $\nu_{1}=0$, and MIMICA used $\mu=0.33$ and $v_{1}=1$. In the WRF model, $\mu=0.33$, and $v_{1}$ is diagnostically calculated based on Martin et al. (1994). UM-CASIM used a different form of the gamma distribution:

$\frac{\mathrm{d} N}{\mathrm{~d} D}=\operatorname{CDNC} \frac{1}{\Gamma\left(1+\nu_{2}\right)} \lambda_{2}{ }^{\left(1+\nu_{2}\right)} D^{\nu_{2}} \exp \left(-\lambda_{2} D\right)$,

where $D$ is the cloud droplet diameter, and $\nu_{2}$ and $\lambda_{2}$ are shape and slope parameters distinct in meaning from $v_{1}$ and $\lambda_{1} . \lambda_{2}$ is defined by

$\lambda_{2}=\left[\frac{\Gamma\left(4+v_{2}\right)}{\Gamma\left(1+\nu_{2}\right)} \frac{\pi \rho}{6 \bar{x}}\right]^{1 / 3}$.

For the purposes of calculating autoconversion, UM-CASIM used a diagnostic $v_{2}$ based on Martin et al. (1994).

\subsection{Sensitivity to prescribed CDNC}

Next, we examine the CDNC03_NOICE case in order to investigate the sensitivity of the model results to a reduction in prescribed CDNC from 30 to $3 \mathrm{~cm}^{-3}$. Figure 6 shows the mass mixing ratios of cloud droplets and rain. All models produce thinner clouds with lower LWCs compared to the higher CDNC case. A stable cloud is produced by MIMICA, with cloud thickness reduced to $\sim 300 \mathrm{~m}$ and cloudtop cloud droplet mass mixing ratios reduced to $\sim 0.2 \mathrm{~g} \mathrm{~kg}^{-1}$, but mixing ratios of rain are similar to those produced with the larger prescribed CDNC. In COSMO-LES, two clouds are produced initially at $\sim 200$ and $\sim 900 \mathrm{~m}$. Available water is removed by precipitation, and the clouds begin to dissipate towards the end of the simulation (note that COSMOLES simulations have ended at $34 \mathrm{~h}$ since 30 August 2008, 

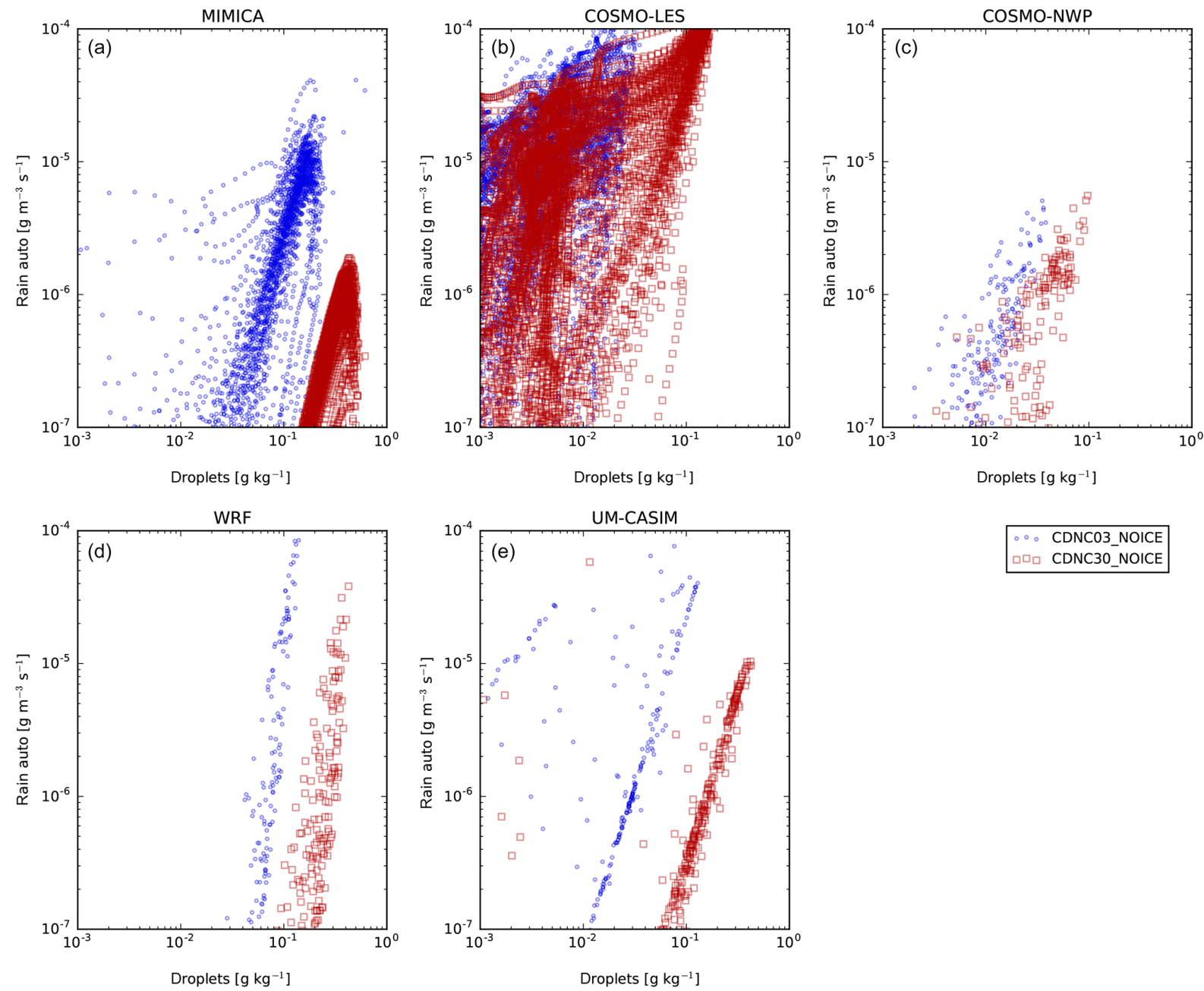

$\because$ CDNCO3 NOICE D CDNC30_NOICE

Figure 5. Tendencies of mixing ratios of cloud water due to autoconversion vs. cloud droplet mass mixing ratios for simulations with prescribed CDNCs and no cloud ice permitted. Results are shown from the (a) MIMICA, (b) COSMO-LES, (c) COSMO-NWP, (d) WRF, and (e) UM-CASIM models. Results from simulations with a prescribed CDNC of $3 \mathrm{~cm}^{-3}$ are shown as blue circles and those with a prescribed $\mathrm{CDNC}$ of $30 \mathrm{~cm}^{-3}$ are shown as red squares.

12:00 UTC). COSMO-NWP produces a cloud with cloud droplet mass mixing ratios reduced to $\sim 0.02 \mathrm{~g} \mathrm{~kg}^{-1}$ that thins and temporarily dissipates towards the end of the simulation. UM-CASIM produces a stable cloud with cloud-top cloud droplet mass mixing ratios reduced to $\sim 0.2 \mathrm{~g} \mathrm{~kg}^{-1}$, with rain mass mixing ratios larger than those predicted when using a prescribed CDNC of $30 \mathrm{~cm}^{-3}$. WRF produces a fog layer between the surface and $\sim 500 \mathrm{~m}$. The reduced LWPs predicted by WRF early in the simulation, compared to the CDNC30_NOICE case, allow for greater longwave cooling of the surface, ultimately creating an inversion layer that tracks the top of the fog layer. This effect would not be reproduced by COSMO-LES, despite the dissolution of the cloud, as the surface temperature in COSMO-LES was prescribed for this study.

Figure 6 also shows the liquid-phase process rates for the CDNC03_NOICE case. The reduction in the prescribed
CDNC values results in an increase in the autoconversion to rain tendencies in MIMICA and UM-CASIM. It can be seen in Fig. 5 that the autoconversion tendencies are increased even after accounting for changes in cloud droplet mass mixing ratios. Within WRF and UM-CASIM, cloud droplet sedimentation tendencies remain similar in magnitude to those in the CDNC30_NOICE simulation. The mass of cloud droplets available to sediment is reduced by increased autoconversion to rain, but this is compensated for by increased fall speeds due to the increased size of the cloud droplets. Rain sedimentation tendencies in WRF and UM-CASIM are also similar in magnitude to the CDNC30_NOICE case. The rates of autoconversion to rain and the rates of sedimentation of rain predicted in COSMO-NWP are similar to those in the CDNC30_NOICE case when the cloud thickness and LWC are greatest, but diminish to much smaller values as the cloud dissipates. Compared to the higher CDNC case, the MIM- 

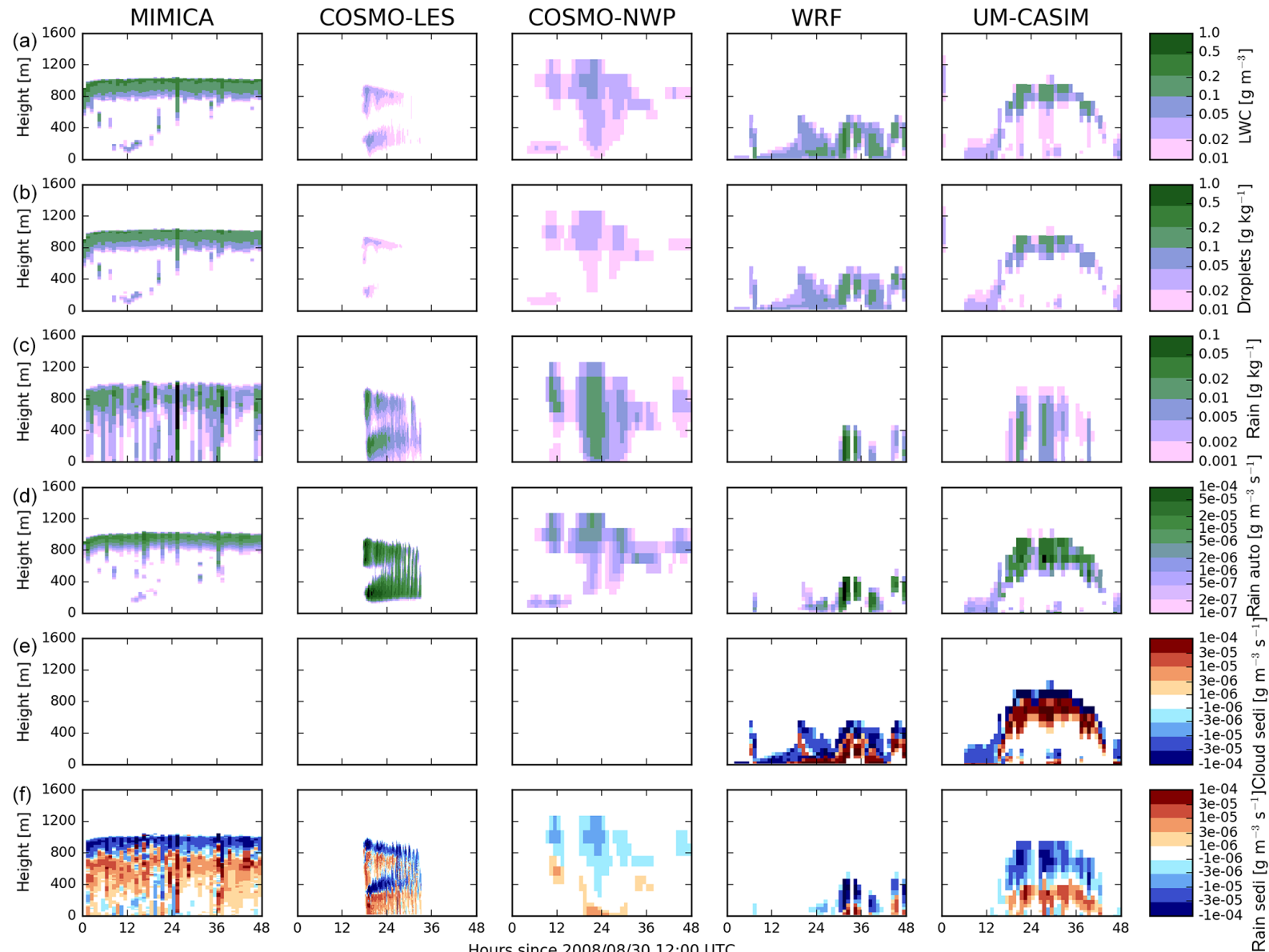

Figure 6. Liquid water contents, cloud and rain mass mixing ratios, and tendencies due to liquid-phase processes for simulations with a prescribed CDNC of $3 \mathrm{~cm}^{-3}$ and no cloud ice permitted (CDNC03_NOICE). (a) Liquid water contents. (b) Mass mixing ratios of cloud droplets. (c) Mass mixing ratios of rain. (d, e, f) Tendencies of mixing ratios of cloud droplets or rain due to (d) autoconversion of cloud droplets to rain, (e) sedimentation of cloud droplets, and (f) sedimentation of rain. Results are shown (from left to right) from the MIMICA, COSMO-LES, COSMO-NWP, WRF, and UM-CASIM models. Note that only WRF and UM-CASIM simulate the sedimentation of cloud droplets.

ICA model predicts larger losses within the cloud through the sedimentation of rain due to the larger mixing ratio of rain predicted in this case. The COSMO-LES model predicts lower mixing ratios of rain for this case relative to the CDNC30_NOICE case as the cloud dissipates. The changes in mass due to sedimentation are therefore lower than in the CDNC30_NOICE case.

\subsection{Sensitivity to activation scheme}

We will now discuss the CCN30fixed_NOICE and CCN80fixed_NOICE cases. These cases differ from the prescribed CDNC cases in that cloud droplet activation is predicted based on a constant background aerosol concentration of either 80 or $30 \mathrm{~cm}^{-3}$ with median diameter $94 \mathrm{~nm}$ and geometric standard deviation of 1.5 instead of being prescribed to be 30 or $3 \mathrm{~cm}^{-3}$.
Figure 7 shows time-averaged profiles of cloud properties for the CDNC30_NOICE, CDNC03_NOICE, CCN30fixed_NOICE, and CCN80fixed_NOICE cases. We average over the period from 12:00 to 24:00 UTC on 31 August (24-36 h since 12:00 UTC, 30 August) in order to exclude the initial period before a stable cloud forms in the NWP models. We note that for the CDNC03 and CDNC30 cases in COSMO-LES, COSMO-NWP, and UM-CASIM, the CDNC is prescribed through activation, but is permitted to vary within cloud due to evaporation and transport. When the background CCN concentration is set to be $30 \mathrm{~cm}^{-3}$, the CDNC within cloud (column a) is $\sim 15 \mathrm{~cm}^{-3}$ in MIMICA, $\sim 25 \mathrm{~cm}^{-3}$ in COSMO-LES, $\sim 15 \mathrm{~cm}^{-3}$ in COSMO-NWP, $\sim 20 \mathrm{~cm}^{-3}$ in WRF, and $\sim 20 \mathrm{~cm}^{-3}$ in UM-CASIM. The differences in activation fractions are more pronounced for the CCN80 cases: MIMICA, COSMO-LES, COSMO-NWP, WRF, and UM-CASIM predict in-cloud CDNCs of $\sim 25$, 
$\sim 60, \sim 20, \sim 40$, and $\sim 60 \mathrm{~cm}^{-3}$, respectively. This diversity in CDNC of $15-20$ or $20-60 \mathrm{~cm}^{-3}$ for the same constant $\mathrm{CCN}$ concentrations underscores the variability that exists in model results and model sensitivities to perturbations in aerosol concentrations. Unless the models are constrained through common forcings and common scientific choices, there will remain diversity in model results and model sensitivity for both LES and NWP models.

There are many model differences making it difficult to assign variations to particular processes, but one pair of models provides some insight as we shall see. These differences are due in part to differences in the activation schemes used in the different models: the activation scheme described in Khvorostyanov and Curry (2006) is used in MIMICA, the scheme described in Nenes and Seinfeld (2003) and Fountoukis and Nenes (2005) is used in COSMO-LES and COSMO-NWP, and the scheme described in Abdul-Razzak et al. (1998) and Abdul-Razzak and Ghan (2000) is used in WRF and UM-CASIM. These differences may also be due to differences in the representation of small-scale turbulence within the models: COSMO-NWP, WRF, and UM-CASIM have horizontal resolutions too coarse to resolve individual updrafts. WRF and UM-CASIM therefore assume minimum updraft velocities for activation as $0.1 \mathrm{~m} \mathrm{~s}^{-1}$. COSMONWP parameterizes the updraft velocity used for activation by adding $0.8 \times \sqrt{\mathrm{TKE}}$ to the grid-resolved updraft velocity; TKE is the turbulent kinetic energy. The fine resolutions of MIMICA and COSMO-LES allow them to resolve these updrafts explicitly. Differences in sink terms across models, such as the collision-coalescence of cloud droplets and cloud droplet sedimentation, would also be expected to contribute to these differences. As WRF and UM-CASIM have the same activation scheme and the same minimum updraft velocity, we infer that remaining differences in CDNC are due to differences in sink terms. For the CCN30fixed case, CDNCs are similar in both models, but CDNCs simulated by UM-CASIM are greater in the CCN80fixed case. Therefore, CDNC sinks must be similar in the CCN30fixed case, but faster for WRF in the CCN80fixed case.

As cloud properties within the tenuous cloud regime are expected to be dependent on $\mathrm{CCN}$ concentrations via changes in CDNC, it is informative to examine how cloud properties are related to the modelled CDNC for these four cases. With the exception of the $\mathrm{CDNC} 03$ case, the vertical cloud extent and cloud droplet mass mixing ratios (column c) are similar across the different cases in MIMICA, COSMO-LES, and UM-CASIM (differences $<100 \mathrm{~m}$ and $<0.1 \mathrm{~g} \mathrm{~kg}^{-1}$, respectively). The COSMO-NWP model (subplot c.iii) shows higher cloud altitudes and cloud droplet mass mixing ratios for the CDNC30 case. The WRF model results (subplot c.iv) generally show an increase in both cloud vertical thickness and cloud height correlated with increasing CDNC. The mass mixing ratios of rain within MIMICA (subplot d.i) and UM-CASIM (subplot d.v) clearly increase with decreasing CDNCs due to increases in autoconversion from cloud droplets (subplots e.i and e.v), mitigated somewhat by increases in rain sedimentation rates (subplots g.i and g.v). For the CCN80fixed case, the CDNC is sufficiently high in UM-CASIM to reduce concentrations of rain below $10-3 \mathrm{~g} \mathrm{~kg}^{-1}$. This effect is present within WRF (subplot d.iv), but is more difficult to discern because of coincident changes in cloud height and thickness. Within COSMOLES (subplot d.ii), there is a weak increase in rain mass mixing ratios with decreasing CDNC until CDNC is reduced to $3 \mathrm{~cm}^{-3}$, at which point rain mass mixing ratios are reduced due to cloud dissipation.

\subsection{Sensitivity to prognostic aerosol}

We now consider the CCN80prog_NOICE case. In these simulations, the aerosol is initialized as in the CCN80fixed_NOICE case, but is then allowed to evolve with time due to advection, removal by cloud droplet activation, and resuspension upon evaporation. Figure 8 shows profiles vs. time of the mass mixing ratios of cloud droplets and rain, CDNC, N50 concentrations, and potential temperature.

For this case, the MIMICA and COSMO-NWP models produce results very similar to those for the CCN80fixed_NOICE case. In COSMO-NWP, the resuspension of aerosol upon the evaporation of cloud droplets and raindrops leads to a build-up of aerosol below cloud, leading to an enhancement of CDNCs at cloud base, particularly after $24 \mathrm{~h}$ of simulation time. The UM-CASIM model produces a cloud that is reduced in vertical extent and liquid water content, with more rain compared to the case without aerosol processing. The reduction in available $\mathrm{CCN}$ by activation reduces $\mathrm{CDNC}$, leading to larger cloud droplets and increased autoconversion to rain. The UCLALES-SALSA model also produces a stable cloud with cloud-top height near $1 \mathrm{~km}$ and cloud droplet mixing ratios of $\sim 0.3 \mathrm{~g} \mathrm{~kg}^{-1}$, but with no autoconversion to rain. Unlike the other models included in this study, UCLALES-SALSA does not assume a gamma distribution for cloud droplets, and instead uses seven sectional bins to represent the cloud droplet size distribution and explicitly calculates drop-drop collisions using the bin representation (see Sect. 3). Therefore, the UCLALES-SALSA model does not necessarily produce any large $(>50 \mu \mathrm{m})$ cloud droplets upon activation, as would be implicitly assumed by a gamma distribution. The UCLALES-SALSA model resolves narrower cloud droplet size distributions than those represented by the other models in this study, with no cloud droplets large enough to trigger partitioning into the rain category. Differences in cloud thickness between MIMICA and UCLALESSALSA (thickening in MIMICA and thinning with time in UCLALES-SALSA) for this case are primarily due to the different subsidence rates as described in Sect. 4. Simulations performed by UCLALES-SALSA using the same lower subsidence rate as the MIMICA simulations yielded a cloud layer with a similar LWP to the MIMICA 

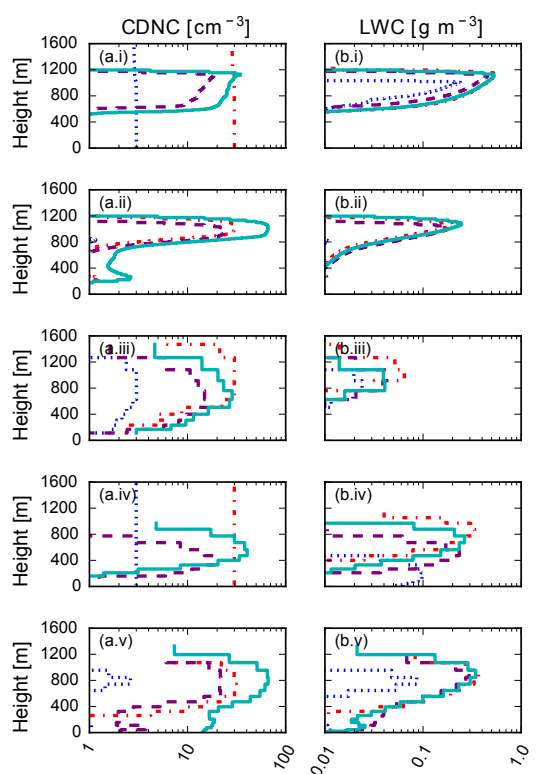
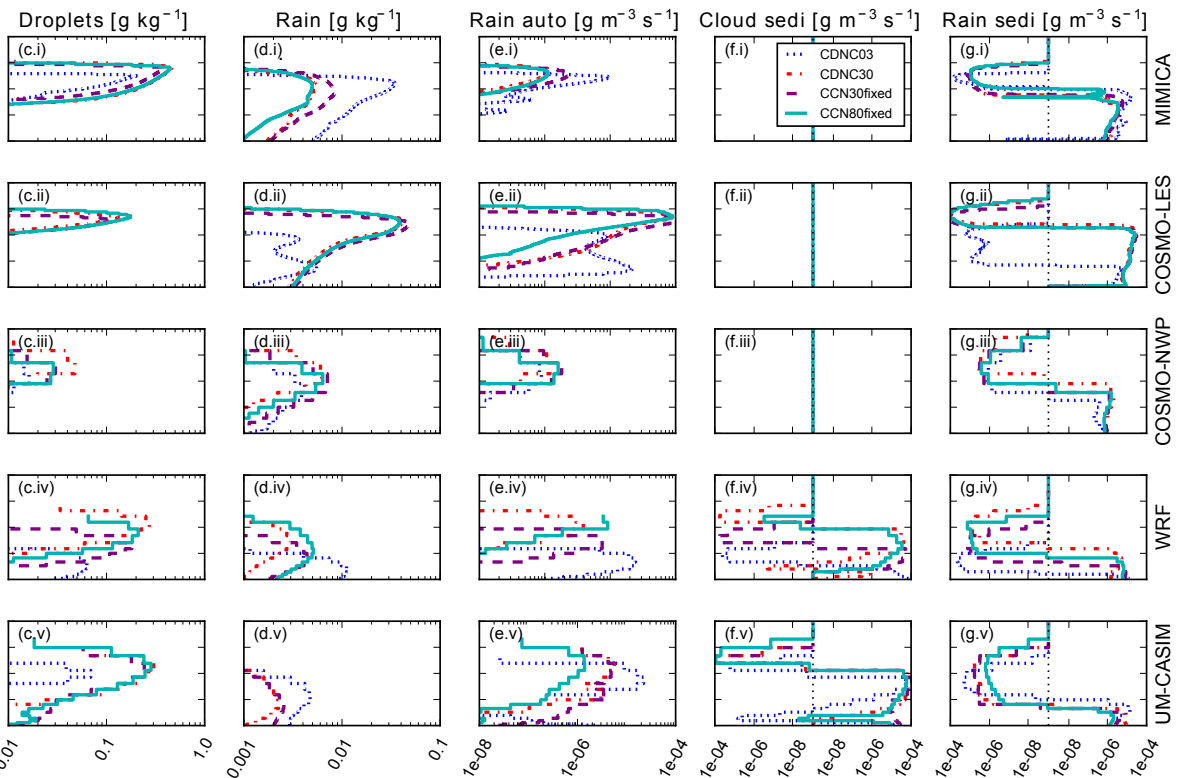

Figure 7. Time-averaged profiles of cloud properties and tendencies due to liquid-phase processes for simulations with no cloud ice permitted. The first letter in subplot labels refers to column and the second to the row. (a) Cloud droplet number concentrations. (b) Liquid water contents. (c) Cloud droplet mass mixing ratios. (d) Rain mass mixing ratios. Rightmost three columns: tendencies of mixing ratios of cloud droplets or rain due to autoconversion of cloud droplets to rain (e), sedimentation of cloud droplets (f), and sedimentation of rain (g). Results are shown (from top to bottom) from the MIMICA (i), COSMO-LES (ii), COSMO-NWP (iii), WRF (iv), and UM-CASIM (v) models. The blue dotted line indicates the CDNC03 case, the red dash-dotted line indicates the CDNC30 case, the purple dashed line indicates the CCN30fixed case, and the solid turquoise line indicates the CCN80fixed case. Note that only WRF and UM-CASIM simulate the sedimentation of cloud droplets.

simulation $\left(\sim 125\right.$ and $140 \mathrm{~g} \mathrm{~m}^{-2}$, respectively), but the cloud layer rose at an unrealistic rate.

When the initial $\mathrm{CCN}$ concentration is reduced to $30 \mathrm{~cm}^{-3}$ (CCN30prog_NOICE; Fig. 9), the UCLALESSALSA model no longer maintains a stable cloud. Instead, the larger size of cloud droplets allows for partitioning into rain, which subsequently removes the available aerosol by sedimentation. As the cloud thins, radiative cooling of the cloud top weakens, resulting in less generation of turbulence. The above-cloud temperature inversion subsequently descends due to subsidence. Within UCLALESSALSA, subsidence only affects the tendencies of temperature and water vapour and does not directly alter advection of aerosols. Therefore the temperature inversion descends into the aerosol-depleted layer, suppressing any further entrainment of aerosol from above the cloud. The reduction in aerosol concentrations further reduces CDNCs, leading to larger cloud droplets and further enhances conversion to rain. The depletion of aerosol therefore results in a positive feedback loop that ends with total dissipation of the cloud. The MIMICA, COSMO-NWP, and UM-CASIM models, conversely, do maintain clouds to the end of the simulation, although the water content of the clouds is reduced. The COSMO-NWP model shows the weakest sensitivity to the decrease in $\mathrm{CCN}$ concentrations, similarly to the weak sensitivity shown in Sect. 5.2 to changes in prescribed CDNC. The vertical extent of the cloud simulated by the MIMICA model decreases with time. This cloud has similar cloud droplet mass mixing ratios to the case with fixed aerosol concentrations (CCN30fixed_NOICE), but is thinner $(\sim 300 \mathrm{~m}$ vs. $\sim 500 \mathrm{~m})$. The CDNC decreases during the simulation to $\sim 2 \mathrm{~cm}^{-3}$ after $48 \mathrm{~h}$, resulting in faster autoconversion rates and larger mixing ratios of rain. Results from the UM-CASIM model are qualitatively similar to those with the higher initial aerosol concentration, but cloud droplet mass mixing ratios and CDNC are lower (0.1 vs. $0.15 \mathrm{~g} \mathrm{~kg}^{-1}$ and $5 \mathrm{vs} .20 \mathrm{~cm}^{-3}$ ). The concurrent reductions in both cloud droplet mass mixing ratios and CDNC yield only small changes in cloud droplet sizes, so there are no large changes in rain autoconversion rates, cloud droplet sedimentation rates, mass mixing ratios of rain, or rain sedimentation rates.

Further reducing the initial $\mathrm{CCN}$ concentration to $3 \mathrm{~cm}^{-3}$ (CCN03prog_NOICE, Fig. 10) results in dissipation of the original cloud in UCLALES-SALSA, MIMICA, and UMCASIM. The results of UCLALES-SALSA are qualitatively similar to the results with an initial CCN concentration of $30 \mathrm{~cm}^{-3}$, except that the cloud dissipates much more quickly. The cloud completely dissipates after less than $6 \mathrm{~h}$ into the simulation, while in the simulation with an initial CCN con- 

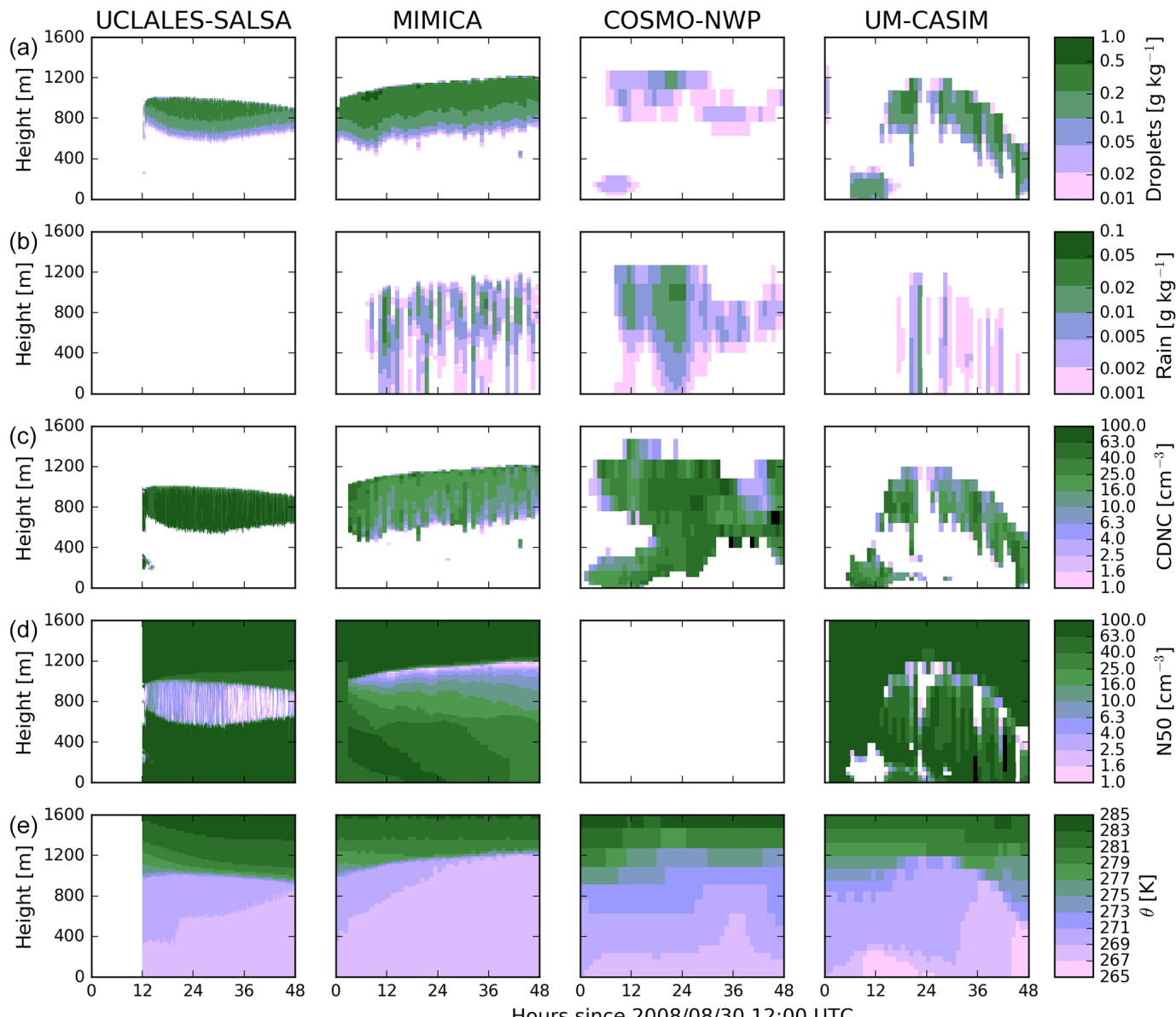

Figure 8. Cloud properties in the simulations with prognostic aerosol and an initial CCN concentration of $80 \mathrm{~cm}^{-3}$ (CCN80prog_NOICE). (a) Cloud droplet mass mixing ratio, (b) rain mass mixing ratio, (c) cloud droplet number concentration, (d) N50 concentration, and (e) potential temperature. Results are shown (from left to right) from the UCLALES-SALSA, MIMICA, COSMO-NWP, and UM-CASIM models. Note that aerosol concentrations and CDNCs are fixed during the $2 \mathrm{~h}$ spin-up period in MIMICA, and N50 concentrations are not available for COSMO-NWP.

centration of $30 \mathrm{~cm}^{-3}$, the formation of rain started after $6 \mathrm{~h}$ of simulation, and complete dissipation of the cloud did not occur until the end of the $36 \mathrm{~h}$ simulation. The original cloud layer in the MIMICA model dissipates after about $36 \mathrm{~h}$ of simulation time. A second cloud layer forms $12 \mathrm{~h}$ from the beginning of the simulation at around $200 \mathrm{~m}$ from the surface and rises to $700 \mathrm{~m}$ by the end of the simulation. Rain falling from the upper cloud layer evaporates before reaching the lower cloud layer. This transports moisture and aerosol vertically closer to the lower cloud layer, where they are subsequently mixed into the lower cloud layer by turbulence. COSMO-NWP maintains a drizzling cloud throughout most of the simulation. Evaporation of cloud droplets and raindrops transports aerosol below cloud, resulting in larger aerosol concentrations and larger CDNCs at cloud base than those predicted by the other models. In UM-CASIM, reduction of the initial aerosol concentration to $3 \mathrm{~cm}^{-3}$ results in dissipation of the cloud by drizzle. The formation and dis- sipation of the cloud is not visible in the centre-of-domain results shown here, but the aerosol number concentrations remain depleted in the air mass where the cloud formed, which passes through the centre of the domain 24-36h from the start of the simulation. The thinning of the cloud layer allows for the cooling of the surface via longwave emission, creating a stable layer near $200 \mathrm{~m}$. This restricts any cloud from forming above this layer. This feedback will not occur in the LES models due to the prescribed surface conditions and fluxes used in our study.

The timescale of aerosol removal depends strongly on the model and the initial CCN concentration. UCLALESSALSA predicts that below-cloud N50 concentrations would be unaffected for initial CCN concentrations of 3 or $80 \mathrm{~cm}^{-3}$ due to a lack of mixing to the surface after cloud dissipation in the former case and a lack of precipitation in the latter case. If the initial $\mathrm{CCN}$ concentration is $30 \mathrm{~cm}^{-3}$, UCLALES-SALSA predicts that N50 concentra- 

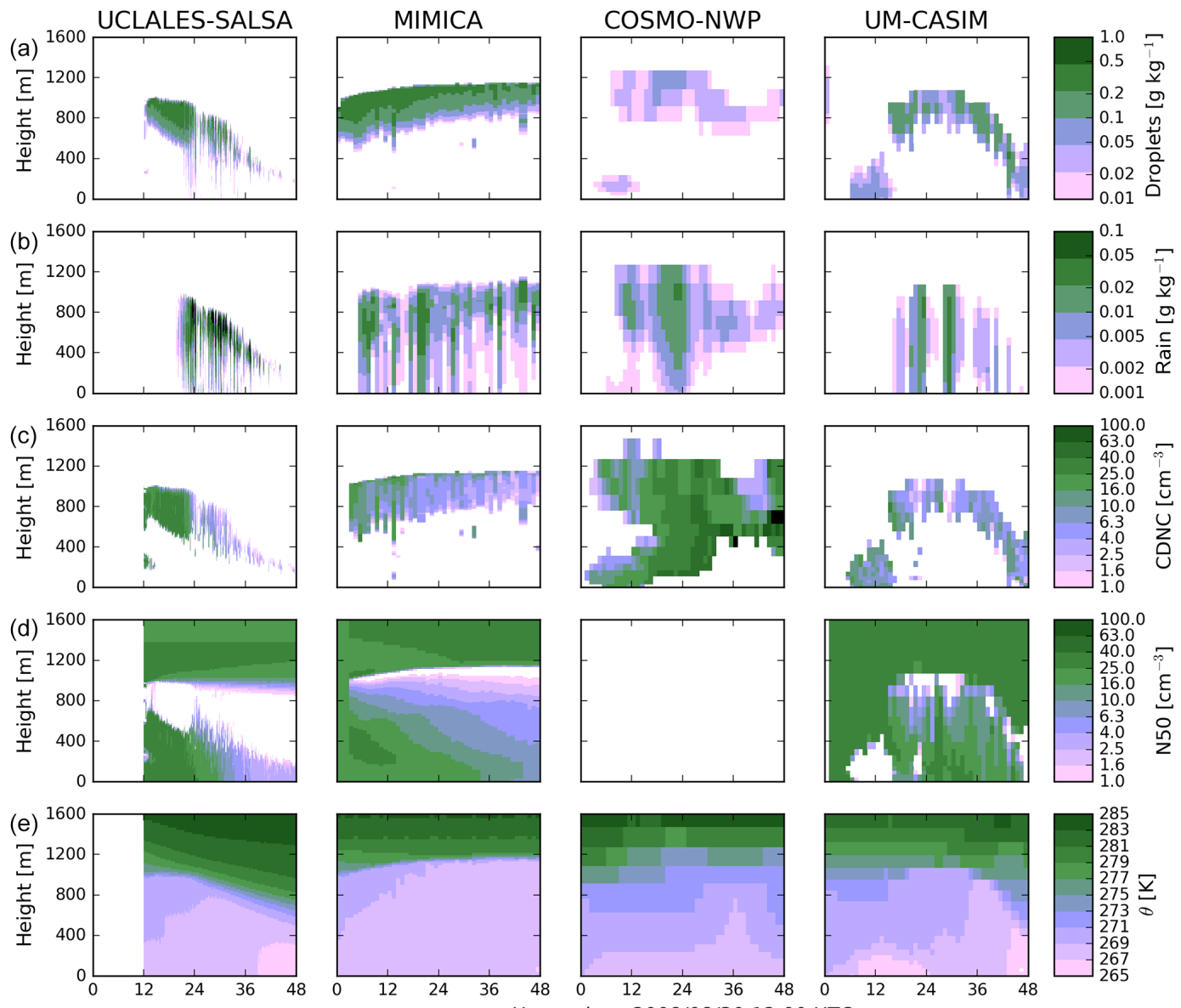

Figure 9. Cloud properties in the simulations with prognostic aerosol and an initial CCN concentration of $30 \mathrm{~cm}^{-3}$ (CCN30prog_NOICE). (a) Cloud droplet mass mixing ratio, (b) rain mass mixing ratio, (c) cloud droplet number concentration, (d) N50 concentration, and (e) potential temperature. Results are shown (from left to right) from the UCLALES-SALSA, MIMICA, COSMO-NWP, and UM-CASIM models. Note that aerosol concentrations and CDNCs are fixed during the $2 \mathrm{~h}$ spin-up period in MIMICA, and N50 concentrations are not available for COSMO-NWP.

tions throughout the boundary layer fall below $1 \mathrm{~cm}^{-3}$ after $36 \mathrm{~h}$. The MIMICA model predicts a steady decrease in surface N50 concentrations for all three prognostic cases simulated, ranging from $\sim 0.4 \mathrm{~cm}^{-3} \mathrm{~h}^{-1}$ for the $80 \mathrm{~cm}^{-3}$ case to $0.05 \mathrm{~cm}^{-3} \mathrm{~h}^{-1}$ for the $3 \mathrm{~cm}^{-3}$ case. Aerosol removal rates are difficult to diagnose from COSMO-NWP and UM-CASIM due to the advection of different air masses being simultaneous with aerosol processing.

The model results shown above demonstrate a robust relationship between decreases in CDNC, either through direct prescription or from the effects of activation and processing, and the thinning or even collapse of the cloud layer. However, the sensitivity of the cloud layer to decreases in CDNC differs between models due to differences in the partitioning of cloud liquid between cloud droplets and rain and differences in the representation of surface properties. In the next section we build on these liquid-only results by adding the complication of ice interactions.

\section{Sensitivity to ice formation}

\subsection{Base case}

Figure 11 shows the liquid and ice water contents from the models when the CDNC is prescribed as $30 \mathrm{~cm}^{-3}$ and the ICNC is prescribed as $0.2 \mathrm{~L}^{-1}$ (CDNC30_ICNC0p20). The IWCs predicted by the models vary by an order of magnitude between the models, with COSMO-LES and WRF predicting IWCs less than $0.002 \mathrm{~g} \mathrm{~m}^{-3}$, but MIMICA producing highly variable IWCs often as great as $0.02 \mathrm{~g} \mathrm{~m}^{-3}$. We note that the IWCs derived from observations are often greater than $0.05 \mathrm{~g} \mathrm{~m}^{-3}$, but the uncertainty could be as great as a factor of 2, as stated in Sect. 2. Even accounting for this uncertainty, all models underestimate the IWC for this case. Any model bias in IWC does not seem to be related to biases in LWC.

Figure 12 shows the mass mixing ratios of cloud droplets, rain, cloud ice crystals, snow, and graupel from the models when the CDNC is prescribed as $30 \mathrm{~cm}^{-3}$ and the ICNC is 

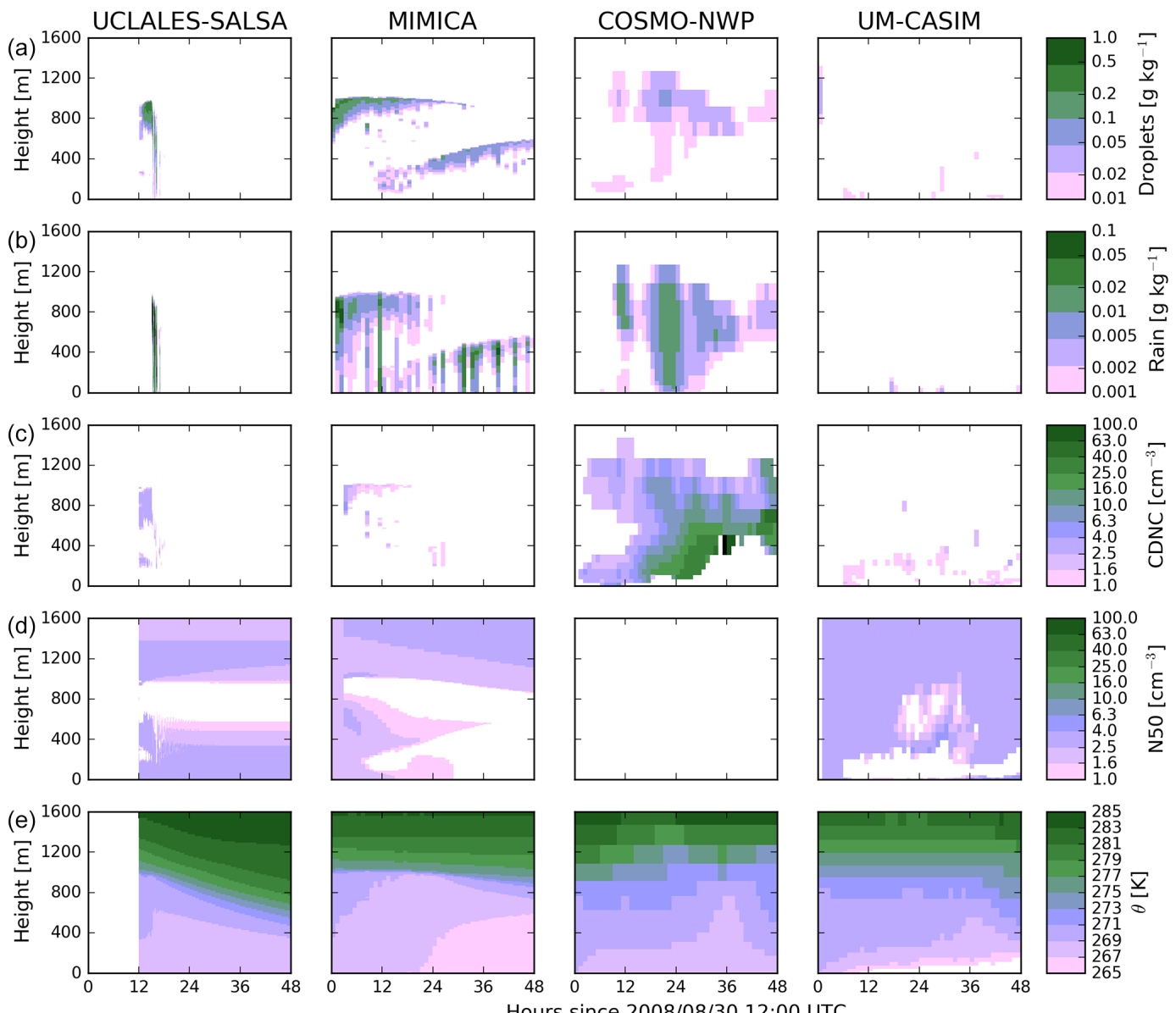

Figure 10. Cloud properties in the simulations with prognostic aerosol and an initial CCN concentration of $3 \mathrm{~cm}^{-3}$ (CCN03prog_NOICE). (a) Cloud droplet mass mixing ratio, (b) rain mass mixing ratio, (c) cloud droplet number concentration, (d) N50 concentration, and (e) potential temperature. Results are shown (from left to right) from the UCLALES-SALSA, MIMICA, and UM-CASIM models. Note that aerosol concentrations and CDNCs are fixed during the $2 \mathrm{~h}$ spin-up period in MIMICA, and N50 concentrations are not available for COSMO-NWP.
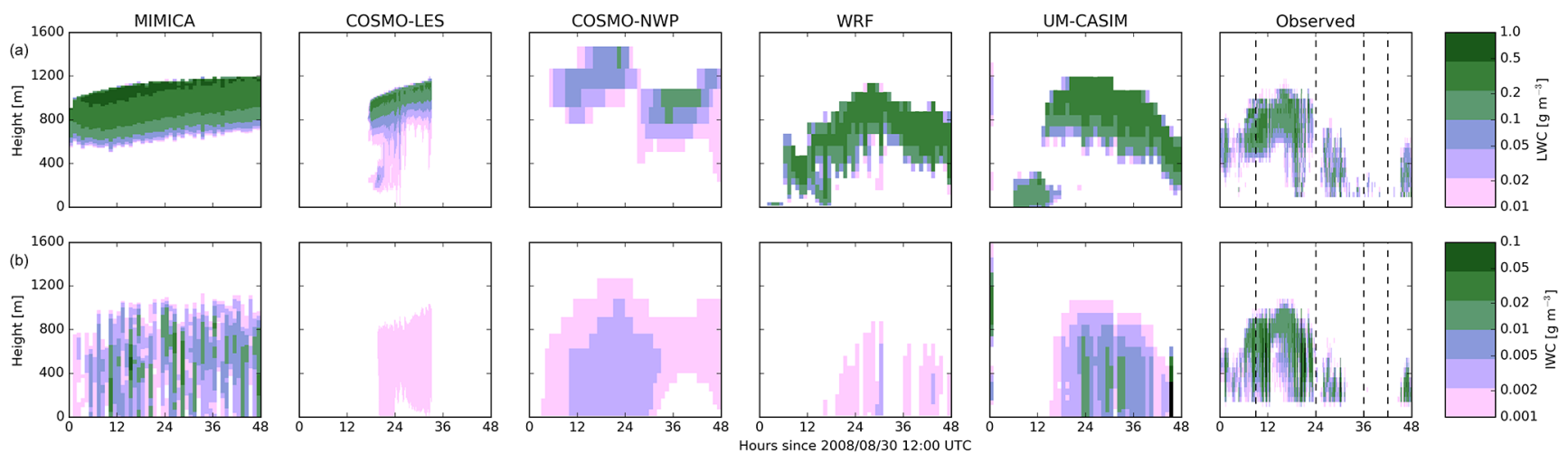

Figure 11. Liquid and ice water content in the simulations with a prescribed CDNC of $30 \mathrm{~cm}^{-3}$ and a prescribed ICNC of $0.2 \mathrm{~L}^{-1}$ (CDNC30_ICNC0p20), and liquid and ice water content derived from observations. (a) Liquid water contents, (b) ice water contents. Results are shown (left to right) from the MIMICA, COSMO-LES, COSMO-NWP, WRF, and UM-CASIM models. Values derived from observations are shown in the rightmost column. Vertical dashed lines indicate the beginnings and endings of the cloudy and nearly cloud-free periods. 
prescribed as $0.2 \mathrm{~L}^{-1}$ (CDNC30_ICNC0p20). We note with comparison to Fig. 3 that the introduction of ice does not change cloud height or cloud depth by more than $100 \mathrm{~m}$ in any model, and cloud mass mixing ratios change by less than $20 \%$ in all models. However, mass mixing ratios of rain are reduced in the results of the MIMICA and WRF models.

The form of frozen mass depends on which model is used: only MIMICA produces a significant amount of graupel, and only WRF predicts that most frozen water would be snow. COSMO-LES, COSMO-NWP, and UM-CASIM predict the frozen water to exist predominantly as cloud ice crystals, but UM-CASIM also predicts a small amount of mass in the snow category. Within MIMICA, any collision between a liquid hydrometeor and a frozen hydrometeor will move the resulting mass to the graupel category. Within all other models, collisions between cloud ice crystals smaller than $160 \mu \mathrm{m}$ and cloud droplets do not form graupel. Collisions between ice crystals larger than $160 \mu \mathrm{m}$ and cloud droplets can produce graupel in COSMO-LES and COSMO-NWP, but the collision and sticking efficiencies are small. So even if large ice crystals are present, this remains a negligible source of graupel. Since cloud ice crystals are the dominant form of frozen hydrometeors in all other models aside from WRF and cloud droplets are the dominant form of liquid hydrometeors in all models, no graupel is formed in COSMO-LES, COSMO-NWP, or UM-CASIM. As mentioned in Sect. 3, the set-up of WRF used in this study does not possess a graupel category, so riming by snow will increase the mass of snow instead of forming graupel in WRF.

In order to examine the causes and implications of these differences in ice between the models, Fig. 13 shows timeaveraged profiles of process rates affecting ice crystals and snow for each of the models for the prescribed CDNC cases. We average over 31 August 2008 from 12:00 to 24:00 UTC in order to exclude the initial period of the NWP models before a stable cloud forms. We note that mass mixing ratios of snow (column b) are often an order of magnitude less than cloud ice mass mixing ratios (column a), but even these small amounts of snow can have significant effects on cloud species or water vapour mixing ratios (columns $\mathrm{f}$ and $\mathrm{h}$ ). Within COSMO-LES, except the CDNC30_ICNC1p00 case, insignificant autoconversion to snow occurs (subplot c.ii) and nearly all frozen cloud mass remains as cloud ice crystals (subplot a.ii). The cloud ice grows by deposition within cloud and sublimates below cloud (subplot g.ii), frequently sublimating completely before reaching the surface. COSMONWP (row iii) behaves similarly to COSMO-LES, but the cloud ice grows by deposition throughout the boundary layer (subplot g.iii). As stated previously, only WRF maintains significant mixing ratios of snow (subplot b.iv). Autoconversion to snow proceeds more quickly than in the other models for the same cloud ice crystal mixing ratios (compare subplots c.iv and a.iv). The snow that is produced through autoconversion subsequently grows efficiently by the riming of cloud droplets (subplot e.iv) and deposition of water vapour (subplot h.iv). UM-CASIM simulates the greatest autoconversion rates of all the models (subplot c.v). This is in part due to UM-CASIM producing the greatest cloud ice crystal mixing ratios of all the models (subplot a.v), but autoconversion proceeds more quickly even for similar cloud ice mixing ratios. The snow produced by UM-CASIM grows efficiently by the deposition and collection of cloud water (subplots h.v and e.v), but also sediments more quickly per unit mass than in any other model (subplot f.v) and sublimates quickly below cloud (subplot h.v), and thus the mass of snow maintained in the atmosphere is small.

The differences in process rates between models are due to both differences in the parameterization of the physical processes and differences in the representation of the size distributions of the frozen cloud species in the different models. Additional contributions to these differences would come from differences in model meteorology and model resolution. In the next section we will examine the sensitivity to ICNC in the context of CCN and CDNC changes.

\subsection{Sensitivity to CDNC, CCN, and ICNC}

\subsubsection{Prescribed CDNC and fixed aerosol simulations}

In order to summarize our results with different prescribed ICNCs, Fig. 14 shows box plots of the LWP (including cloud droplets and rain), IWP (including cloud ice crystals, snow, and graupel), and surface net LW radiation from each model for all of the CDNC30, CDNC03, CCN30fixed, and CCN80fixed cases during the period after 31 August 2008, 12:00 UTC. For the three NWP models, we show a similar figure with spatial statistics for a $100 \mathrm{~km}^{2}$ area as Fig. S2. The NWP models show more variation across time because they include time-varying large-scale features not considered by the LES models. We note that we do not expect the prescribed CDNC or prescribed $\mathrm{CCN}$ cases to capture the cloudy to nearly cloud-free transition, so we do not attempt to sample the models during these observed time periods. However, if the tenuous cloud hypothesis is correct, the cloud states resulting in each model for the cases with greater prescribed CDNC and CCN concentrations would be expected to be more representative of the cloudy period, and the cloud states for the cases with lesser prescribed CDNC and CCN concentrations would be expected to be more representative of the nearly cloud-free period. Our choice of time period allows $24 \mathrm{~h}$ for the models to reach a representative state and consists of $24 \mathrm{~h}$ of modelled time for the three NWP models and MIMICA. The COSMO-LES results include $7 \mathrm{~h}$ of model time before averaging, and the averaging period covers $9 \mathrm{~h}$ of modelled time. We note that the choice of averaging period is arbitrary, but our conclusions are not sensitive to changes in the averaging period, with a few exceptions: first, the initial period required for each NWP model to form a liquid cloud above the surface must be excluded (6-18 h). Second, the MIMICA model predicts increased glaciation of the 

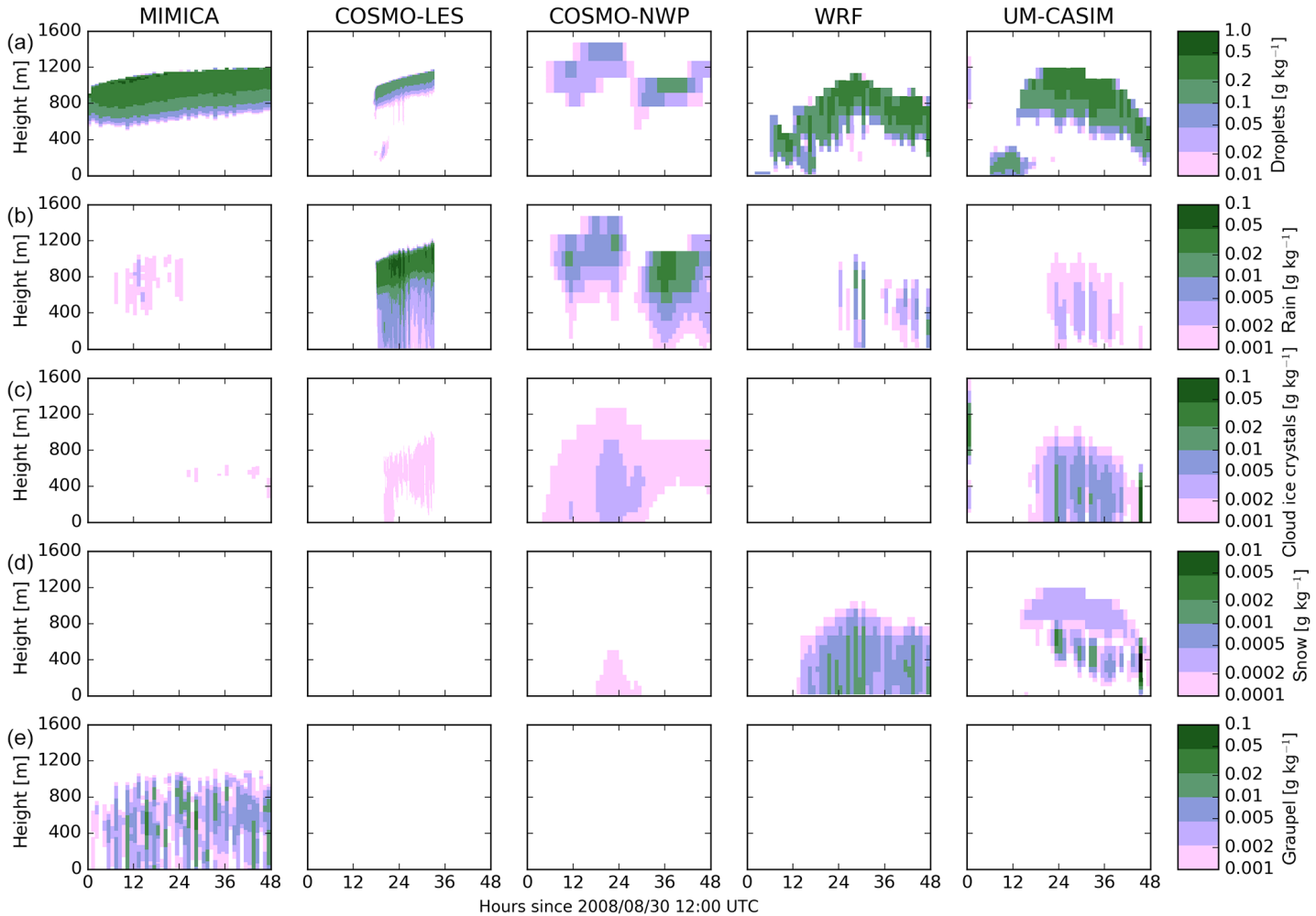

Figure 12. Cloud mass mixing ratios in the simulations with a prescribed CDNC of $30 \mathrm{~cm}^{-3}$ and a prescribed ICNC of $0.2 \mathrm{~L}^{-1}$ (CDNC30_ICNC0p20). (a) Mass mixing ratios of cloud droplets, (b) mass mixing ratios of rain, (c) mass mixing ratios of cloud ice crystals, (d) mass mixing ratios of snow, and (e) mass mixing ratios of graupel. Results are shown (left to right) from the MIMICA, COSMO-LES, COSMO-NWP, WRF, and UM-CASIM models. Note that WRF does not possess a graupel category.
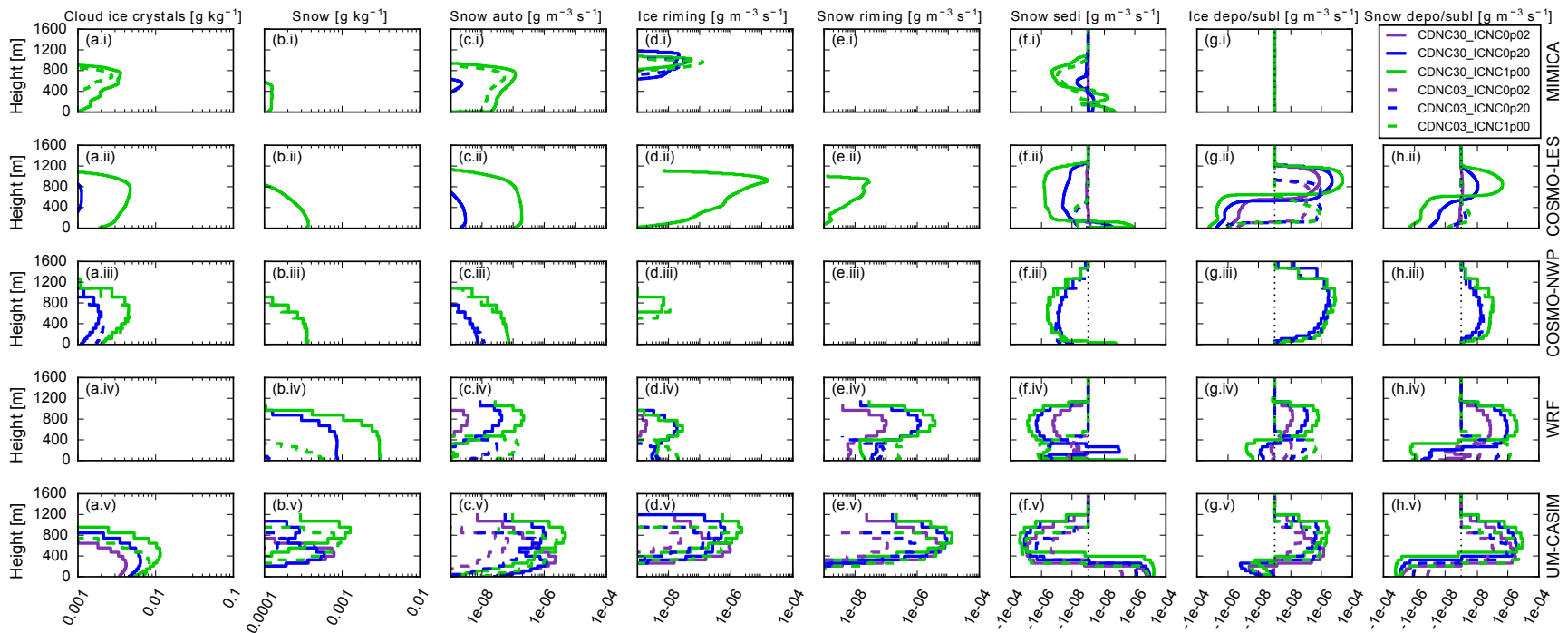

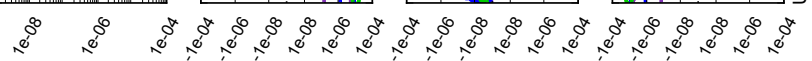

Figure 13. Tendencies of ice and snow mass due to processes affecting frozen cloud mass for the prescribed CDNC simulations. The first letter in subplot labels refers to column and the second to the row. Mass mixing ratios of cloud ice (a) and snow (b), tendencies of cloud ice and snow mass due to autoconversion to snow (c), riming by cloud ice (d), riming by snow (e), sedimentation of snow (f), deposition + sublimation of cloud ice (g), and deposition + sublimation of snow (h). Results shown (from top to bottom) for MIMICA (i), COSMO-LES (ii), COSMO-NWP (iii), WRF (iv), and UM-CASIM (v). 
cloud with time in the two ICNC1p00 cases, with LWP, IWP, and surface net LW radiation steadily decreasing in magnitude with time. Third, the UM-CASIM model predicts that the cloud altitude decreases after $\sim 36 \mathrm{~h}$ of simulation for all cases in which a cloud is simulated, as can be seen in e.g. Figs. 3, 6, 8, and 11. This leads to decreases in LWP, IWP, and the magnitude of the surface net LW radiation if this time period is included. Fourth, the COSMO-NWP model predicts a stable frozen cloud in the CDNC30_ICNC1p00, CDNC03_ICNC0p20, and CDNC03_ICNC1p00 cases until $30 \mathrm{~h}$ of simulation time (31 August, 18:00 UTC). After $30 \mathrm{~h}$ a drizzling mixed-phase cloud forms, similar to the results shown after $30 \mathrm{~h}$ of simulation in Fig. 12. All of these effects will be discussed further later in this section.

Figure 14 also shows the observed interquartile range for the cloudy and nearly cloud-free periods as hatched and shaded regions, respectively. These periods are defined and discussed in Sect. 2. The interquartile range plotted accounts for time variance in the observations. We do not explicitly account for observational error, but random observational error will contribute to this time variance.

The median LWP predicted by the models spans nearly 2 orders of magnitude, from $2.5 \mathrm{~g} \mathrm{~m}^{-2}$ for the COSMO-LES CDNC03_ICNC1p00 simulation to $190 \mathrm{~g} \mathrm{~m}^{-2}$ for the MIMICA CDNC30_ICNC0p02 case. The MIMICA model tends to produce the largest LWPs. COSMO-LES produces the smallest LWPs for the CDNC03 cases, and COSMO-NWP produces the smallest LWPs for all other cases simulated. Every model for every value of ICNC shows an increase in LWP as CDNC is increased from 3 to $30 \mathrm{~cm}^{-3}$, and almost every model shows an increase in LWP as the fixed $\mathrm{CCN}$ concentration is increased from 30 to $80 \mathrm{~cm}^{-3}$. However, the magnitude of this increase varies greatly from model to model. Notably, COSMO-NWP shows the smallest differences in LWP between different cases, with no significant change in LWP between the CCN30fixed and CCN80fixed cases. We noted earlier in Sect. 5.1 that a greater fraction of cloud droplet mass autoconverts to rain in COSMO-NWP compared to MIMICA, WRF, or UM-CASIM, regardless of the prescribed CDNC value chosen for activation. Therefore, a larger fraction of the liquid in the COSMO-NWP results consists of rain as opposed to cloud droplets compared to the other models. As the CDNC is decreased, either through changes in the prescribed CDNC or changes in the CCN concentration, further losses in cloud droplet mass mixing ratios are partially compensated for by increases in rain mass, reducing differences in total LWP. We showed in Sect. 5 that MIMICA generally predicts less autoconversion than the other models; as a result the proportion of the LWP composed of rain in MIMICA is less, so it shows the greatest sensitivity to changes in CDNC.

In general, the model results show decreases in LWP with increasing ICNC, but these changes are generally small relative to the sensitivity to our choice of representation of cloud droplet activation. Larger prescribed ICNCs increase the re- moval of liquid water through riming and through deposition via the Wegener-Bergeron-Findeisen process (see Fig. 13). The MIMICA model predicts almost complete glaciation for $\mathrm{ICNC}=1 \mathrm{~L}^{-1}$, and therefore produces a much reduced LWP for those cases. LWPs within COSMO-NWP are reduced to near zero for the first $30 \mathrm{~h}$ of the CDNC30_ICNC1p00, CDNC03_ICNC0p20, and CDNC03_ICNC1p00 COSMONWP simulations due to glaciation of the cloud, but after $30 \mathrm{~h}$ a drizzling cloud forms with LWP not strongly dependent on the prescribed ICNC concentration.

Median IWPs predicted by the models for non-zero ICNC range from ice free for the MIMICA CDNC03_ICNCOp02 case to $7.2 \mathrm{~g} \mathrm{~m}^{-2}$ for the UM-CASIM CDNC30_ICNC1p00 case. The model results show increases in IWP with prescribed ICNC, except the MIMICA ICNC1p00 cases in which the cloud glaciates and dissipates. If a shorter averaging period was used, the IWPs for these two cases would be larger than those for the ICNC0p20 cases. The IWPs predicted by WRF and UM-CASIM are roughly linear with respect to the prescribed ICNC concentration over the range used here: each 10-fold increase in ICNC increases the IWP by roughly a factor of 10 . Within COSMO-LES, increases in IWP are sub-linear with respect to increases in ICNC: the IWP increases by a factor between 5.3 and 7.6 as the prescribed ICNC is increased by a factor of 10 from 0.02 to $0.2 \mathrm{~L}^{-1}$. IWPs are also sub-linear with respect to ICNC in COSMO-NWP: the IWP increases by a factor of either 2.8 or 3.3 as the prescribed ICNC is increased by a factor of 5 from 0.2 to $1 \mathrm{~L}^{-1}$. Median IWPs also generally increase with increases in $\mathrm{CDNC}$ or increases in $\mathrm{CCN}$ concentrations due to the increased cloud water available to freeze and form ice.

The net surface LW radiation within each model is generally well correlated with the LWP within each model. As has been discussed in Intrieri et al. (2002), Arctic clouds have a net warming effect over sea ice due to the high albedo of the surface and the low angle of incoming solar radiation. Variability in the surface net LW is greater for cases with lower LWPs than for cases with high LWPs, as LW emission by clouds saturates for large values of LWP. The LW dependence on LWP is stronger in the LES models than in the NWP models. This is primarily due to the experimental set-up: within the NWP models the surface temperature is predicted in part based on radiative flux balance, whereas it is held fixed in the LES models. When there is less cloud, less LW radiation is re-emitted back towards the surface, and the surface would be expected to cool more quickly, which would then reduce the LW emission from the surface.

For the MIMICA, COSMO-LES, WRF, and UM-CASIM models, a CDNC between 3 and $30 \mathrm{~cm}^{-3}$ could be prescribed that yields an LWP within the interquartile range of observed LWP during the cloudy period, but this prescribed CDNC value is not consistent across models. Unfortunately, in-cloud CDNC measurements were not available for the period studied here, so the models cannot be constrained based on this measurement. Also, as discussed above, the CDNC-LWP re- 


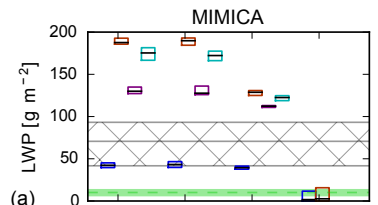

(a)
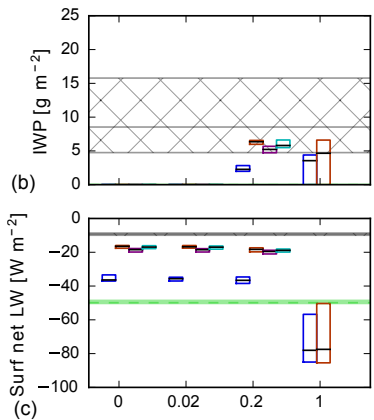
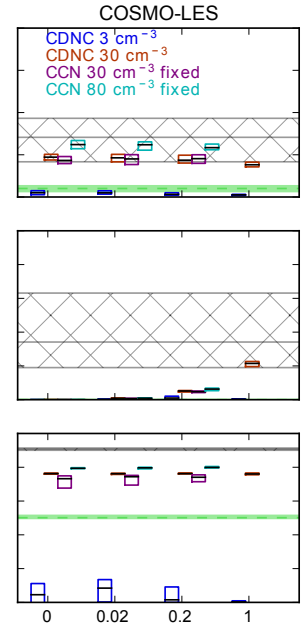

COSMO-NWP
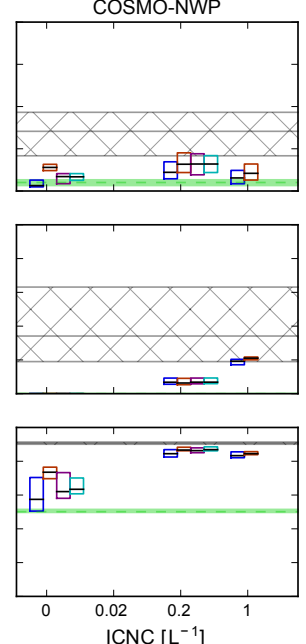

WRF
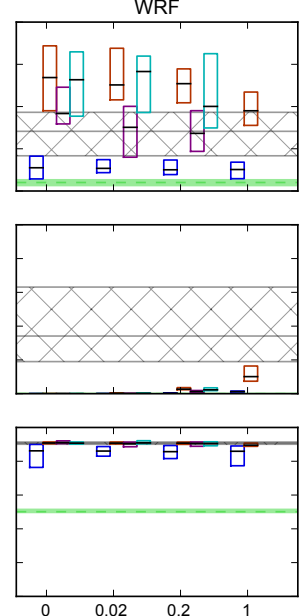
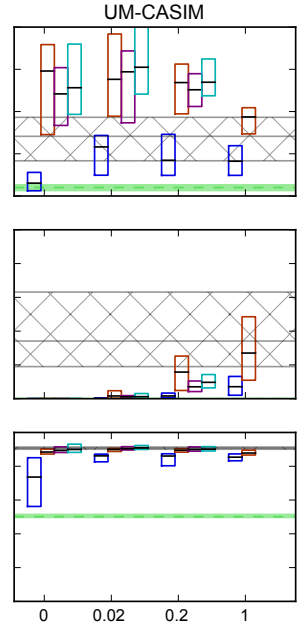

Figure 14. Water paths and net longwave radiation for all simulations without aerosol processing. (a) Liquid water path, (b) ice water path, (c) surface net longwave radiation. Each subplot shows results from a single model. From left to right: MIMICA, COSMO-LES, COSMONWP, WRF, and UM-CASIM. Simulations with prescribed CDNCs of 3 (CDNC03) and $30 \mathrm{~cm}^{-3}$ (CDNC30) are shown as blue and red boxes, respectively, and simulations with prescribed CCN concentrations of 30 (CCN30fixed) and $80 \mathrm{~cm}^{-3}$ (CCN80fixed) are shown as purple and turquoise boxes, respectively. Within each subplot, the ICNC is increased from left to right as $0,0.02,0.2$, and $1 \mathrm{~L}^{-1}$. Boxes show the interquartile range over model results after 31 August 12:00 UTC, and the black horizontal lines denote the medians. Hatched regions indicate observed interquartile range for the cloudy period, and the green shaded regions indicate the range for the nearly cloud-free period.

lationship for this case appears to be dominated by the partitioning of liquid water between cloud droplets and rain within each model, which is often tunable through the cloud droplet size distribution parameters or a parameter in the autoconversion scheme such as the maximum cloud droplet size. LWPs consistent with those observed during the nearly cloud-free period were produced by simulations in which the cloud dissipated, regardless of the mechanism of cloud dissipation. The cloud glaciates in MIMICA simulations with a prescribed ICNC of $1 \mathrm{~L}^{-1}$, and the cloud temporarily glaciates in the CDNC30_ICNC1p00, CDNC03_ICNC0p20, and CDNC03_ICNC1p00 COSMO-NWP simulations. The cloud rains out in COSMO-LES simulations with a prescribed CDNC of $3 \mathrm{~cm}^{-3}$ and in the COSMO-NWP simulation with a prescribed CDNC of $3 \mathrm{~cm}^{-3}$ and no cloud ice.

The median IWP from each model for every case is less than the median observed IWP for the cloudy period. However, as discussed in Sect. 2, there is a large uncertainty in the observed IWP, which is partially responsible for the large time variance in the observed IWP. For COSMOLES, COSMO-NWP, and UM-CASIM, a prescribed ICNC of $1 \mathrm{~L}^{-1}$ is required to produce a median IWP within the interquartile range of the observed IWP. The MIMICA model produces an IWP within this range with an ICNC of $0.2 \mathrm{~L}^{-1}$. As noted previously, the MIMICA model predicts glaciation and dissipation if an ICNC of $1 \mathrm{~L}^{-1}$ is prescribed, and the averaging period used here includes the dissipation of the cloud. If a shorter averaging period was used, the IWP for these two cases would be larger than those for the ICNCOp20 cases.

Median surface net LW radiation from nearly all WRF and UM-CASIM simulations with LWP $>75 \mathrm{~g} \mathrm{~m}^{-2}$ is consistent with the observations for the cloudy period. However, despite larger LWPs, MIMICA predicts too much LW emission. This is due in part to the prescribed surface temperatures in our experimental set-up being too warm, as described above. This also contributes to the discrepancy between the LW emission observed during the nearly cloud-free period and the MIMICA and COSMO-LES results with LWPs consistent with the nearly cloud-free period.

\subsubsection{Prognostic aerosol simulations}

Figure 15 shows a similar plot to Fig. 14 for the cases with prognostic aerosol processing. For the COSMO-NWP and UM-CASIM models, we show a similar figure with spatial statistics for a $100 \mathrm{~km}^{2}$ area as Fig. S3. Here we also include $\mathrm{N} 50$ concentrations at $20 \mathrm{~m}$ from the surface for consistency with the measurement inlet height. Note that N50 concentrations are not available from COMSO-NWP. N50 concentrations from the other three models for the CCN30prog simulations overlap those observed for the cloudy period, except for the UM-CASIM CCN30prog_NOICE case, which yields greater N50 concentrations. N50 concentrations from MIMICA and UM-CASIM for the CCN03prog cases overlap those observed for the nearly cloud-free period. The UCLALES-SALSA CCN03prog_NOICE simulation predicts very little depletion of N50 from the initial values, 
as discussed in Sect. 5.4. The MIMICA and UM-CASIM models simulate clouds with reduced vertical extents, lower LWCs, and therefore lower LWPs with prognostic aerosol than with time-invariant aerosol concentrations. Similarly, IWPs are also lower due to the lower amount of liquid water available to freeze. The LWPs simulated by MIMICA with an initial CCN concentration of $30 \mathrm{~cm}^{-3}$ are consistent with observations during the cloudy period. UM-CASIM and UCLALES-SALSA produce LWPs consistent with the cloudy period with initial CCN concentrations of $80 \mathrm{~cm}^{-3}$. All simulations in which the cloud layer dissipated (initial $\mathrm{CCN}$ concentration of $3 \mathrm{~cm}^{-3}$ in all models and initial $\mathrm{CCN}$ concentration of $30 \mathrm{~cm}^{-3}$ with UCLALES-SALSA) produce LWPs within measurement error of the nearly cloud-free period.

When the initial $\mathrm{CCN}$ concentration is $80 \mathrm{~cm}^{-3}$, UCLALES-SALSA, MIMICA, and UM-CASIM predict that below-cloud N50 concentrations remain above $50 \%$ of initial N50 concentrations (see Fig. 8). This reduction in aerosol number is due to in-cloud processing and drizzle deposition to the surface offset by the resuspension of aerosol from evaporation and sublimation of hydrometeors. An initial $\mathrm{CCN}$ concentration of $30 \mathrm{~cm}^{-3}$ yields $\mathrm{N} 50$ concentrations at $20 \mathrm{~m}$ consistent with observations for all cases in which this information is available, except for the UCLALES-SALSA case and the UM-CASIM case with no ice nucleation. In the former, the cloud dissipates and N50 is depleted throughout the boundary layer. The latter case produces the least rain of all the cases simulated with an initial $\mathrm{CCN}$ concentration of $30 \mathrm{~cm}^{-3}$ and has the least removal of aerosol to the surface. Median N50 at $20 \mathrm{~m}$ for all cases with an initial CCN concentration of $3 \mathrm{~cm}^{-3}$ is below $1 \mathrm{~cm}^{-3}$, except for the UCLALES-SALSA results, in which $\mathrm{N} 50$ is depleted in cloud, but no mixing of the depleted layer with lower layers occurs following cloud dissipation (see Fig. 10). There is no clear effect across models of changes in prescribed ICNC on modelled N50 concentrations.

\section{Conclusions}

In this study, we have compared the results of three LES models and three NWP models for a tenuous cloud regime case study observed during the 2008 ASCOS field campaign. We began with simulations using prescribed CDNC and prescribed ICNC, progressed to simulations with prognostic CDNC based on a constant aerosol size distribution, and finally showed simulations using prognostic aerosol processing along with prognostic CDNC. Our key findings are the following.

Our modelling results strongly support the hypothesis that the LWC, and hence the radiative effects, of these clouds are highly sensitive to $\mathrm{CCN}$ concentrations; in order words, they are CCN limited. For the observed meteorological conditions, all models predict that the cloud does not collapse as observed when the CCN concentration is held constant at the value observed during the cloudy period, but the clouds thin or collapse as the CCN concentration is reduced. Cloud dissipation due to glaciation is predicted only by the MIMICA model and only for a prescribed ICNC of $1 \mathrm{~L}^{-1}$, the largest value tested in this study. As the IWP was generally underestimated compared to the observed IWP, it is possible that the contribution of glaciation to dissipation was also underestimated. Global and regional models with either prescribed CDNCs or prescribed aerosol concentrations would not reproduce cloud dissipation due to low $\mathrm{CCN}$ concentrations and therefore would not capture this source of variability in cloud LWC and hence cloud radiative effects. This suggests that linkages between aerosol and clouds need to be considered for weather and climate predictions in this region. In particular, we recommend that studies are carried out to determine if $\mathrm{CCN}$-controlled cloudiness has a remote effect on important weather phenomena such as mid-latitude blocking. If it does, then we recommend that aerosol-cloud interactions be included to capture the impact on the more populated mid-latitude regions.

All models predict increasing LWP with increasing CDNC, either through prescribed CDNC values or changes in available CCN concentrations. The increases in LWP and subsequent decreases in surface net LW radiation with increasing $\mathrm{CCN}$ concentrations or prescribed CDNC suggest that increased aerosol concentrations in the high Arctic during the clean summer period would have a warming effect on the surface, potentially resulting in more thinning of sea ice or a delay in autumn freeze-up events. Our results suggest this effect would be most dramatic when $\mathrm{CCN}$ concentrations increase beyond the threshold value required to prevent cloud dissipation.

Most models simulate increasing IWP with increasing prescribed ICNC and decreasing LWP with increasing ICNC due to increased efficiency of the WBF process with increased ICNC. This is consistent with the results of previous investigations of the sensitivity of Arctic mixed-phase cloud to the representation of ice nucleation (e.g. Avramov and Harrington, 2010; Fridlind et al., 2012; Harrington et al., 1999; Jiang et al., 2000; Klein et al., 2009; Morrison et al., 2003; Morrison et al., 2005b; Morrison et al., 2011; Ovchinnikov et al., 2014; Pinto, 1998; Prenni et al., 2007; Solomon et al., 2009; Young et al., 2017). However, the effects of changes in ICNC on LWP and surface net LW were generally weaker than the effects of changes in CDNC or CCN across the ranges tested in this study. This is consistent with results found by Possner et al. (2017) in which the total water path and net surface LW were to first order determined by CDNC or CCN concentrations, rather than INP concentrations, for $\mathrm{CCN}$ and INP perturbations of similar magnitude as considered in this study. However, for larger INP perturbations (exceeding $1 \mathrm{~L}^{-1}$ ) in a low-INP regime, INP perturbations were seen to potentially offset, if not reverse, the cloud response to $\mathrm{CCN}$ perturbations. If INP concentrations in the Arctic were 
(a)

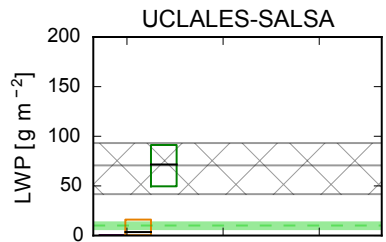

(b)

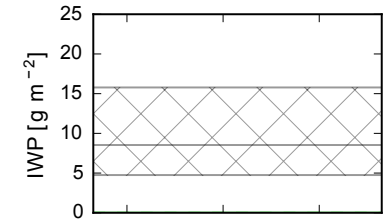

(c)

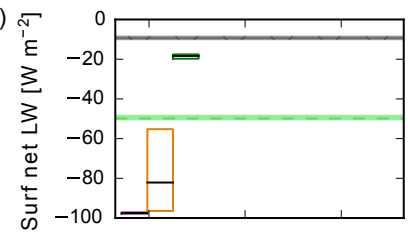

(d)

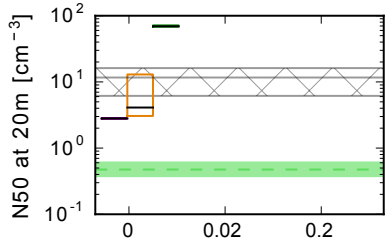

MIMICA
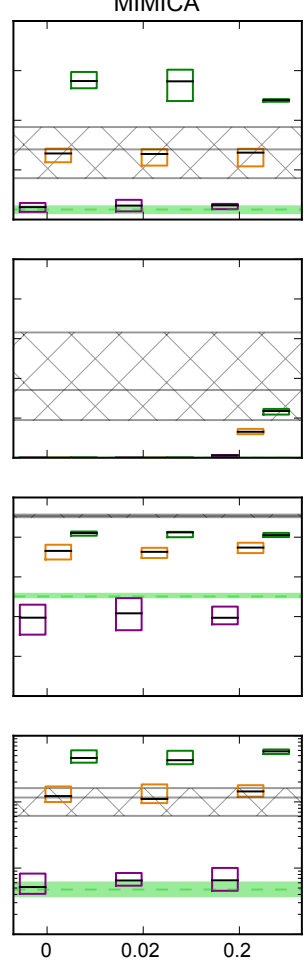

COSMO-NWP
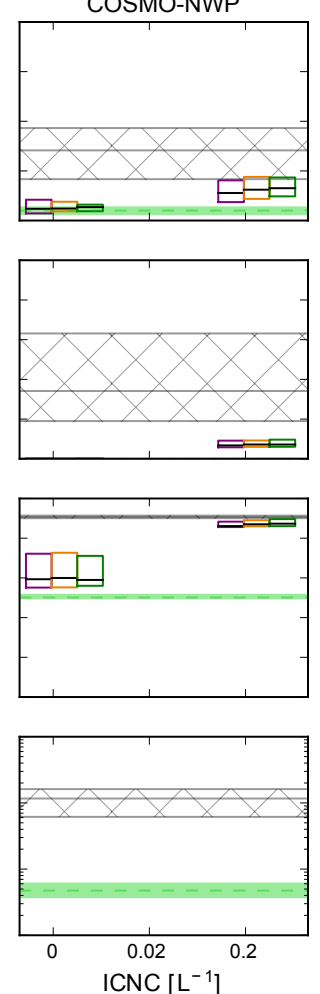

UM-CASIM
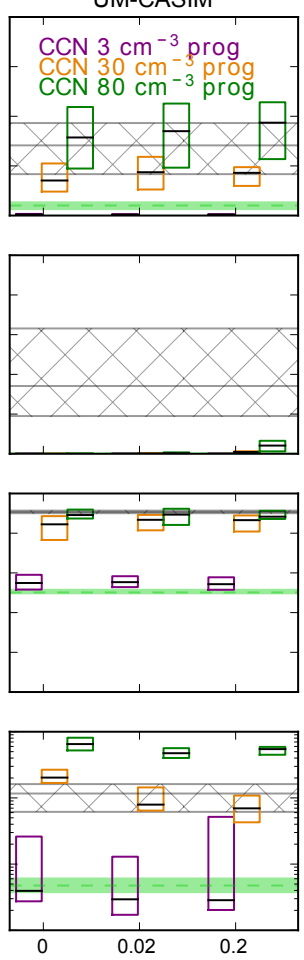

Figure 15. Cloud and surface properties for all simulations with prognostic aerosol. (a) Liquid water path, (b) ice water path, (c) surface net longwave radiation, and (d) N50 concentrations at $20 \mathrm{~m}$ from the surface. Each subplot shows results from a single model. From left to right: UCLALES-SALSA, MIMICA, COSMO-NWP, and UM-CASIM. Simulations with an initial CCN concentration of 3 (CCN03prog), 30 (CCN30prog), and $80 \mathrm{~cm}^{-3}$ (CCN80prog) are shown as purple, orange, and green boxes, respectively. Within each subplot, the ICNC is increased from left to right as $0,0.02$, and $0.2 \mathrm{~L}^{-1}$. Boxes show the interquartile range over model results after 31 August 12:00 UTC, and the black horizontal lines denote the medians. Hatched regions indicate the observed interquartile range for the cloudy period, and the green shaded regions indicate the range for the nearly cloud-free period. Note that N50 concentrations are not available from the COSMO-NWP model.

to increase beyond $1 \mathrm{~L}^{-1}$ due to changes in transport from low latitudes or increases in local emissions, these could induce large changes in cloud properties. However, this value is greater than those observed previously in the high Arctic (Bigg, 1996; Bigg and Leck, 2001).

Despite some common model behaviours, there is large inter-model diversity in the sensitivities of the models to changes in CDNC or CCN concentrations. The change in LWP due to an increase in prescribed CDNC from 3 to $30 \mathrm{~cm}^{-3}$ varies from $\sim 10$ to $\sim 100 \mathrm{~g} \mathrm{~m}^{-2}$ depending on the choice of model alone. Cloud dissipation was predicted by the COSMO-LES, COSMO-NWP, and WRF models for a prescribed $\mathrm{CDNC}$ of $3 \mathrm{~cm}^{-3}$, suggesting that the critical CDNC for these models was between 3 and $30 \mathrm{~cm}^{-3}$. The critical CDNC for the other models must be less than $3 \mathrm{~cm}^{-3}$. In the prognostic aerosol cases, the critical initial $\mathrm{CCN}$ concentration was between 30 and $80 \mathrm{~cm}^{-3}$ for the UCLALESSALSA model and between 3 and $30 \mathrm{~cm}^{-3}$ for the MIMICA and UM-CASIM models. The COSMO-NWP model did not predict dissipation of the cloud for any of the prog- nostic aerosol cases. We did not test the sensitivity of these critical values to model processes, but it is likely that they are sensitive to the specific set-up of each model used in this study, specifically regarding cloud droplet size distributions and the representation of the autoconversion of cloud droplets to rain. Faster autoconversion rates per unit cloud droplet mass are associated with lower sensitivities in all cloud properties to changes in prescribed $\mathrm{CDNC}$ or $\mathrm{CCN}$ concentrations. Large differences in autoconversion rates per unit cloud droplet mass were simulated despite a similar treatment of autoconversion in four of the models, even in cases with prescribed cloud droplet activation and no frozen cloud processes permitted. Our results therefore suggest that some caution is necessary in interpreting the results of any single model, including the sensitivities of model results to perturbations in aerosol concentrations. Properly estimating aerosol-cloud interactions requires careful consideration regarding the representation of cloud droplet size distributions, as well as the choice of autoconversion scheme and the parameters set therein if an empirical formulation is chosen. 
Our results also suggest that observations should aim to constrain the representation of rain formation and extend the validity of parameterizations to the Arctic domain. We therefore recommend that future observational campaigns aim to perform in situ observations of cloud LWC, IWC, and hydrometeor size distributions, as well as aerosol size and concentration profiles above and below cloud.

The strength of aerosol sources will be critical for the stability of tenuous Arctic clouds. When aerosol removal by activation into cloud droplets was included in the simulations, this decreased simulated CDNCs and LWPs. The rate of depletion of potential $\mathrm{CCN}$ within the boundary layer varied strongly between different models and depending on the initial aerosol concentration. For greater initial aerosol concentrations, precipitation formation was suppressed, decreasing the removal of aerosol to the surface. This supports a positive feedback mechanism whereby increasing aerosol concentrations suppress drizzle formation, reducing the sink of aerosol to the surface. We note that we did not investigate the replenishment of CCN by surface sources or by aerosol nucleation and growth, but Igel et al. (2017) have shown that cloud-top entrainment is important for CDNC (and hence cloud radiative properties) in this case. Entrainment would be included in the results presented here, but as we applied constant initial $\mathrm{CCN}$ concentrations throughout the simulated atmosphere, the above-cloud aerosol concentration available for entrainment was identical to the initial boundary layer aerosol concentration.

A potentially important feedback is that cooling of the sea-ice surface following cloud dissipation increases atmospheric stability near the surface, further suppressing cloud formation. Surface fluxes were predicted to be small by the NWP models so long as a sufficiently thick cloud layer was simulated (surface fluxes were prescribed in the LES models). However, under thin-cloud or cloud-free conditions, the cooling of the surface due to LW emission increased the stability of the near-surface atmospheric layer. The WRF model with a prescribed CDNC of $3 \mathrm{~cm}^{-3}$ predicts that any subsequent cloud will be constrained to a shallow mixed layer at the surface, resulting in surface fog (Fig. 6). This effect can also be seen in the potential temperature profiles predicted by UM-CASIM for the CCNO3prog_NOICE case (Fig. 10). Therefore, this suggests that linkages between clouds, surface temperatures, and atmospheric stability may need to be considered for weather and climate predictions in this region.

We primarily focus on cloud microphysical processes in this work, but it is important to also note the contribution of large-scale atmospheric circulation patterns to cloud cover and thickness (e.g. Kay and Gettelman, 2009) as well as sea ice (e.g. Serreze and Stroeve, 2015). However, our results highlight the sensitivity of high Arctic clouds to CCN concentrations, the importance of the model representation of rain formation in clouds for correctly capturing this sensitivity, and the interactions between clouds, surface temperatures, and atmospheric stability. Future studies of the interac- tions between Arctic clouds, sea ice, and climate must take account of all of these findings.

There are many aspects of high Arctic aerosol-cloud interactions that were beyond the scope of this study to address. Future studies should aim to address the possible role of aerosol replenishment by new-particle formation, surface sources, and transport using models that include coupled aerosols and chemistry with active sources and sinks. The formation of new clouds or fog after dissipation events as aerosol concentrations are replenished also needs to be investigated. More case studies based on additional observational campaigns need to be performed. Uncertainty analyses are necessary to explore the simultaneous contributions of multiple compensating factors. More investigation of surface thermodynamics and feedbacks is also necessary.

Data availability. The intercomparison model output used for our analysis is available at https://doi.org/10.5281/zenodo.1326922 (Stevens et al., 2018).

Supplement. The supplement related to this article is available online at: https://doi.org/10.5194/acp-18-11041-2018-supplement.

Author contributions. RS led the experiment design and analysis and was the primary author of the paper. Experiments using the UCLALES-SALSA, MIMICA, COSMO-LES, COSMO-NWP, WRF, and UM-CASIM models were performed by TR, AD, KL, $\mathrm{AP}$ and GE, CD, and RS, respectively. Necessary development and support for the UCLALES-SALSA, MIMICA, COSMO-LES, COSMO-NWP, WRF, and UM-CASIM models were provided by TR, SR, JT, AL, and HK, AD and AE, KL and CH, AP, GE, and UL, CD and PC, and RS, AH, BS, JW, and PF, respectively. RS, $\mathrm{KL}, \mathrm{CD}, \mathrm{AD}, \mathrm{AP}, \mathrm{GE}, \mathrm{TR}, \mathrm{CH}, \mathrm{AE}, \mathrm{KC}$, and $\mathrm{PF}$ all contributed to the experiment design, analysis, and writing of the paper.

Competing interests. The authors declare that they have no conflict of interest.

Special issue statement. This article is part of the special issue "BACCHUS - Impact of Biogenic versus Anthropogenic emissions on Clouds and Climate: towards a Holistic UnderStanding (ACP/AMT/GMD inter-journal SI)". It is not associated with a conference.

Acknowledgements. We thank the two anonymous reviewers for their comments on this paper. We gratefully acknowledge support from the European Union's Seventh Framework Programme (FP7/2007-2013) with the project Impact of Biogenic versus Anthropogenic emissions on Clouds and Climate: towards a Holistic UnderStanding (BACCHUS; grant no. 603445) and the European Research Council projects ECLAIR (grant no. 646857) 
and C2Phase (grant no. 714062). We acknowledge the use of the MONSooN system, a collaborative facility supplied under the Joint Weather and Climate Research Programme, a strategic partnership between the UK Met Office and the Natural Environment Research Council. We also acknowledge the use of the JASMIN system operated by Centre for Environmental Data Archival (CEDA) as well as the Swiss National Supercomputing Centre (CSCS). Birgit Wehner, Douglas Orsini, Maria Martin, and Staffan Sjögren are much appreciated for providing the size-resolved particle number and the CCN observations. Caroline Leck and Michael Tjernström are specifically thanked for their coordination of ASCOS. The Swedish Polar Research Secretariat provided access to the icebreaker Oden and logistical support. We would like to thank Joseph Sedlar, Thorsten Mauritsen, and Matthew Shupe for the observational data reprinted in this paper and for their comments on an early version of the paper.

Edited by: Daniel J. Cziczo

Reviewed by: two anonymous referees

\section{References}

Abdul-Razzak, H. and Ghan, S. J.: A parameterization of aerosol activation: 2. Multiple aerosol types, J. Geophys. Res.-Atmos., 105, 6837-6844, https://doi.org/10.1029/1999JD901161, 2000.

Abdul-Razzak, H., Ghan, S. J., and Rivera-Carpio, C.: A parameterization of aerosol activation: 1. Single aerosol type, J. Geophys. Res.-Atmos., 103, 6123-6131, https://doi.org/10.1029/97JD03735, 1998.

Avramov, A. and Harrington, J. Y.: Influence of parameterized ice habit on simulated mixed phase Arctic clouds, J. Geophys. Res., 115, 1-14, https://doi.org/10.1029/2009JD012108, 2010.

Bigg, E. K.: Ice forming nuclei in the high Arctic, Tellus B, 48, 223-233, https://doi.org/10.1034/j.1600-0889.1996.t01-100007.x, 1996.

Bigg, E. K. and Leck, C.: Cloud-active particles over the central Arctic Ocean, J. Geophys. Res.-Atmos., 106, 32155-32166, https://doi.org/10.1029/1999JD901152, 2001.

Bigg, E. K., Leck, C., and Nilsson, D.: Sudden changes in arctic atmospheric aerosol concentrations during summer and autumn, Tellus B, 48, 254-271, https://doi.org/10.1034/j.16000889.1996.t01-1-00009.x, 1996.

Birch, C. E., Brooks, I. M., Tjernström, M., Shupe, M. D., Mauritsen, T., Sedlar, J., Lock, A. P., Earnshaw, P., Persson, P. O. G., Milton, S. F., and Leck, C.: Modelling atmospheric structure, cloud and their response to $\mathrm{CCN}$ in the central Arctic: ASCOS case studies, Atmos. Chem. Phys., 12, 3419-3435, https://doi.org/10.5194/acp-12-3419-2012, 2012.

Boisvert, L. N. and Stroeve, J. C.: The Arctic is becoming warmer and wetter as revealed by the Atmospheric Infrared Sounder, Geophys. Res. Lett., 42, 4439-4446, https://doi.org/10.1002/2015GL063775, 2015.

Chan, M. A. and Comiso, J. C.: Arctic Cloud Characteristics as Derived from MODIS, CALIPSO, and CloudSat, J. Climate, 26, 3285-3306, https://doi.org/10.1175/JCLI-D-12-00204.1, 2013.

Chang, R. Y.-W., Leck, C., Graus, M., Müller, M., Paatero, J., Burkhart, J. F., Stohl, A., Orr, L. H., Hayden, K., Li, S.-M., Hansel, A., Tjernström, M., Leaitch, W. R., and Abbatt, J.
P. D.: Aerosol composition and sources in the central Arctic Ocean during ASCOS, Atmos. Chem. Phys., 11, 10619-10636, https://doi.org/10.5194/acp-11-10619-2011, 2011.

Clough, S. A., Shephard, M. W., Mlawer, E. J., Delamere, J. S., Iacono, M. J., Cady-Pereira, K., Boukabara, S., and Brown, P. D.: Atmospheric radiative transfer modeling: A summary of the AER codes, J. Quant. Spectrosc. Ra., 91, 233-244, https://doi.org/10.1016/j.jqsrt.2004.05.058, 2005.

Corbett, J. J., Lack, D. A., Winebrake, J. J., Harder, S., Silberman, J. A., and Gold, M.: Arctic shipping emissions inventories and future scenarios, Atmos. Chem. Phys., 10, 9689-9704, https://doi.org/10.5194/acp-10-9689-2010, 2010.

Curry, J. A., Schramm, J. L., and Ebert, E. E.: Impact of clouds on the surface radiation balance of the Arctic Ocean, Meteorol. Atmos. Phys., 51, 197-217, https://doi.org/10.1007/BF01030494, 1993.

Curry, J. A., Hobbs, P. V., King, M. D., Randall, D. A., Minnis, P., Isaac, G. A., Pinto, J. O., Uttal, T., Bucholtz, A., Cripe, D. G., Gerber, H., Fairall, C. W., Garrett, T. J., Hudson, J., Intrieri, J. M., Jakob, C., Jensen, T., Lawson, P., Marcotte, D., Nguyen, L., Pilewskie, P., Rangno, A., Rogers, D. C., Strawbridge, K. B., Valero, F. P. J., Williams, A. G., and Wylie, D.: FIRE arctic clouds experiment, B. Am. Meteorol. Soc., 81, 5-29, https://doi.org/10.1175/15200477(2000)081<0005:FACE>2.3.CO;2, 2000.

Ekman, A. M. L., Wang, C., Ström, J., and Krejci, R.: Explicit Simulation of Aerosol Physics in a Cloud-Resolving Model: Aerosol Transport and Processing in the Free Troposphere, J. Atmos. Sci., 63, 682-696, https://doi.org/10.1175/JAS3645.1, 2006.

Fan, J., Ovtchinnikov, M., Comstock, J. M., McFarlane, S. A., and Khain, A.: Ice formation in Arctic mixed-phase clouds: Insights from a 3-D cloud-resolving model with size-resolved aerosol and cloud microphysics, J. Geophys. Res., 114, D04205, https://doi.org/10.1029/2008JD010782, 2009.

Fountoukis, C. and Nenes, A.: Continued development of a cloud droplet formation parameterization for global climate models, J. Geophys. Res.-Atmos., 110, 1-10, https://doi.org/10.1029/2004JD005591, 2005.

Fridlind, A. M., van Diedenhoven, B., Ackerman, A. S., Avramov, A., Mrowiec, A., Morrison, H., Zuidema, P., and Shupe, M. D.: A FIRE-ACE/SHEBA Case Study of Mixed-Phase Arctic Boundary Layer Clouds: Entrainment Rate Limitations on Rapid Primary Ice Nucleation Processes, J. Atmos. Sci., 69, 365-389, https://doi.org/10.1175/JAS-D-11-052.1, 2012.

$\mathrm{Fu}, \mathrm{Q}$. and Liou, K. N.: Parameterization of the Radiative Properties of Cirrus Clouds, J. Atmos. Sci., 50, 2008-2025, https://doi.org/10.1175/15200469(1993)050<2008:POTRPO>2.0.CO;2, 1993.

Furtado, K. and Field, P.: The Role of Ice Microphysics Parametrizations in Determining the Prevalence of Supercooled Liquid Water in High-Resolution Simulations of a Southern Ocean Midlatitude Cyclone, J. Atmos. Sci., 74, 2001-2021, https://doi.org/10.1175/JAS-D-16-0165.1, 2017.

Garratt, J.: Review: the atmospheric boundary layer, Earth-Sci. Rev., 37, 89-134, https://doi.org/10.1016/0012-8252(94)900264, 1994.

Grosvenor, D. P., Field, P. R., Hill, A. A., and Shipway, B. J.: The relative importance of macrophysical and cloud albedo changes for aerosol-induced radiative effects in closed-cell stra- 
tocumulus: insight from the modelling of a case study, Atmos. Chem. Phys., 17, 5155-5183, https://doi.org/10.5194/acp17-5155-2017, 2017.

Halliwell, C.: Unified Model Documentation Paper 028 Subgrid Turbulence Scheme, Unified Model Documentation Paper 28, 2014.

Harrington, J. Y., Reisin, T., Cotton, W. R., and Kreidenweis, S. M.: Cloud resolving simulations of Arctic stratus part II: Transition-season clouds, Atmos. Res., 51, 45-75, https://doi.org/10.1016/S0169-8095(98)00098-2, 1999.

Heintzenberg, J. and Leck, C.: The summer aerosol in the central Arctic 1991-2008: did it change or not?, Atmos. Chem. Phys., 12, 3969-3983, https://doi.org/10.5194/acp-123969-2012, 2012.

Herzog, H.-J., Schubert, U., Vogel, G., Fiedler, A., and Kirchner, R.: LLM - the high-resolving nonhydrostatic simulation model in the DWD - project LITFASS. Part I modelling technique and simulation method, COSMO Technical Report No. 4, 1-68, Deutscher Wetterdienst, Offenbach, Germany, 2002a.

Herzog, H. J., Vogel, G., and Schubert, U.: LLM - a nonhydrostatic model applied to high-resolving simulations of turbulent fluxes over heterogeneous terrain, Theor. Appl. Climatol., 73, 67-86, https://doi.org/10.1007/s00704-002-0694-4, 2002b.

Hines, K. M. and Bromwich, D. H.: Simulation of Late Summer Arctic Clouds during ASCOS with Polar WRF, Mon. Weather Rev., 145, 521-541, https://doi.org/10.1175/MWR-D-16-0079.1, 2017.

Hines, K. M., Bromwich, D. H., Bai, L., Bitz, C. M., Powers, J. G., and Manning, K. W.: Sea Ice Enhancements to Polar WRF, Mon. Weather Rev., 143, 2363-2385, https://doi.org/10.1175/MWRD-14-00344.1, 2015.

Igel, A. L., Ekman, A. M., Leck, C., Tjernström, M., Savre, J., and Sedlar, J.: The free troposphere as a potential source of arctic boundary layer aerosol particles, Geophys. Res. Lett., 44, 70537060, https://doi.org/10.1002/2017GL073808, 2017.

Intrieri, J. M., Fairall, C. W., Shupe, M. D., Persson, P. O. G., Andreas, E. L., Guest, P. S., and Moritz, R. E.: An annual cycle of Arctic surface cloud forcing at SHEBA, J. Geophys. Res., 107, 8039, https://doi.org/10.1029/2000JC000439, 2002.

Jiang, H., Cotton, W. R., Pinto, J. O., Curry, J. A., and Weissbluth, M. J.: Cloud Resolving Simulations of Mixed-Phase Arctic Stratus Observed during BASE: Sensitivity to Concentration of Ice Crystals and Large-Scale Heat and Moisture Advection, J. Atmos. Sci., 57, 2105-2117, https://doi.org/10.1175/15200469(2000)057<2105:CRSOMP>2.0.CO;2, 2000.

Kapsch, M. L., Graversen, R. G., Tjernström, M., and Bintanja, R.: The effect of downwelling longwave and shortwave radiation on Arctic summer sea ice, J. Climate, 29, 1143-1159, https://doi.org/10.1175/JCLI-D-15-0238.1, 2016.

Kay, J. E. and Gettelman, A.: Cloud influence on and response to seasonal Arctic sea ice loss, J. Geophys. Res.-Atmos., 114, 118, https://doi.org/10.1029/2009JD011773, 2009.

Khvorostyanov, V. I. and Curry, J. A.: Aerosol size spectra and $\mathrm{CCN}$ activity spectra: Reconciling the lognormal, algebraic, and power laws, J. Geophys. Res.-Atmos., 111, 1-15, https://doi.org/10.1029/2005JD006532, 2006.

Klein, S. A., McCoy, R. B., Morrison, H., Ackerman, A. S., Avramov, A., de Boer, G., Chen, M., Cole, J. N. S., Del Genio, A. D., Falk, M., Foster, M. J., Fridlind, A., Golaz, J.-C., Hashino,
T., Harrington, J. Y., Hoose, C., Khairoutdinov, M. F., Larson, V. E., Liu, X., Luo, Y., McFarquhar, G. M., Menon, S., Neggers, R. A. J., Park, S., Poellot, M. R., Schmidt, J. M., Sednev, I., Shipway, B. J., Shupe, M. D., Spangenberg, D. A., Sud, Y. C., Turner, D. D., Veron, D. E., von Salzen, K., Walker, G. K., Wang, Z., Wolf, A. B., Xie, S., Xu, K.-M., Yang, F., and Zhang, G.: Intercomparison of model simulations of mixed-phase clouds observed during the ARM Mixed-Phase Arctic Cloud Experiment. I: single-layer cloud, Q. J. Roy. Meteor. Soc., 135, 979-1002, https://doi.org/10.1002/qj.416, 2009.

Klingebiel, M., de Lozar, A., Molleker, S., Weigel, R., Roth, A., Schmidt, L., Meyer, J., Ehrlich, A., Neuber, R., Wendisch, M., and Borrmann, S.: Arctic low-level boundary layer clouds: in situ measurements and simulations of mono- and bimodal supercooled droplet size distributions at the top layer of liquid phase clouds, Atmos. Chem. Phys., 15, 617-631, https://doi.org/10.5194/acp-15-617-2015, 2015.

Kokkola, H., Korhonen, H., Lehtinen, K. E. J., Makkonen, R., Asmi, A., Järvenoja, S., Anttila, T., Partanen, A.-I., Kulmala, M., Järvinen, H., Laaksonen, A., and Kerminen, V.-M.: SALSA - a Sectional Aerosol module for Large Scale Applications, Atmos. Chem. Phys., 8, 2469-2483, https://doi.org/10.5194/acp-8-24692008, 2008.

Kupiszewski, P., Leck, C., Tjernström, M., Sjogren, S., Sedlar, J., Graus, M., Müller, M., Brooks, B., Swietlicki, E., Norris, S., and Hansel, A.: Vertical profiling of aerosol particles and trace gases over the central Arctic Ocean during summer, Atmos. Chem. Phys., 13, 12405-12431, https://doi.org/10.5194/acp-13-124052013, 2013.

Lannerfors, H., Heintzenberg, J., and Hansson, H. C.: A comprehensive study of physical and chemical parameters of the Arctic summer aerosol; results from the Swedish expedition Ymer-80, Tellus B, 35, 40-54, https://doi.org/10.1111/j.16000889.1983.tb00006.x, 1983.

Leaitch, W. R., Korolev, A., Aliabadi, A. A., Burkart, J., Willis, M. D., Abbatt, J. P. D., Bozem, H., Hoor, P., Köllner, F., Schneider, J., Herber, A., Konrad, C., and Brauner, R.: Effects of $20-100 \mathrm{~nm}$ particles on liquid clouds in the clean summertime Arctic, Atmos. Chem. Phys., 16, 11107-11124, https://doi.org/10.5194/acp-16-11107-2016, 2016.

Leck, C. and Svensson, E.: Importance of aerosol composition and mixing state for cloud droplet activation over the Arctic pack ice in summer, Atmos. Chem. Phys., 15, 2545-2568, https://doi.org/10.5194/acp-15-2545-2015, 2015.

Leck, C., Bigg, E. K., Covert, D. S., Heintzenberg, J., Maenhaut, W., Nilsson, E. D., and Wiedensohler, A.: Overview of the atmospheric research program during the International Arctic Ocean Expedition of 1991 (IAOE-91) and its scientific results, Tellus B, 48, 136-155, https://doi.org/10.3402/tellusb.v48i2.15833, 1996.

Leck, C., Nilsson, E. D., Bigg, E. K., and Bäcklin, L.: Atmospheric program on the Arctic Ocean Expedition 1996 (AOE96): An overview of scientific goals, experimental approach, and instruments, J. Geophys. Res.-Atmos., 106, 32051-32067, https://doi.org/10.1029/2000JD900461, 2001.

Leck, C., Norman, M., Bigg, E. K., and Hillamo, R.: Chemical composition and sources of the high Arctic aerosol relevant for cloud formation, J. Geophys. Res., 107, 4135, https://doi.org/10.1029/2001JD001463, 2002. 
Leck, C., Tjernström, M., Matrai, P., Swietlicki, E., and Bigg, K.: Can marine micro-organisms influence melting of the Arctic pack ice?, EOS T. Am. Geophys. Un., 85, 25-36, https://doi.org/10.1029/2004EO030001, 2004.

Lilly, D. K.: A proposed modification of the Germano subgridscale closure method, Phys. Fluids A-Fluid, 4, 633-635, https://doi.org/10.1063/1.858280, 1992.

Lloyd, G., Choularton, T. W., Bower, K. N., Crosier, J., Jones, H., Dorsey, J. R., Gallagher, M. W., Connolly, P., Kirchgaessner, A. C. R., and Lachlan-Cope, T.: Observations and comparisons of cloud microphysical properties in spring and summertime Arctic stratocumulus clouds during the ACCACIA campaign, Atmos. Chem. Phys., 15, 3719-3737, https://doi.org/10.5194/acp15-3719-2015, 2015.

Lock, A. P., Brown, A. R., Bush, M. R., Martin, G. M., and Smith, R. N. B.: A New Boundary Layer Mixing Scheme. Part I: Scheme Description and Single-Column Model Tests, Mon. Weather Rev., 128, 3187-3199, https://doi.org/10.1175/15200493(2000)128<3187:ANBLMS>2.0.CO;2, 2000.

Lock, A. P., Edwards, J. M., and Boutle, I. A.: Unified Model Documentation Paper 024 The Parametrization of Boundary Layer Processes, Met Office, 2015.

Loewe, K., Ekman, A. M. L., Paukert, M., Sedlar, J., Tjernström, M., and Hoose, C.: Modelling micro- and macrophysical contributors to the dissipation of an Arctic mixed-phase cloud during the Arctic Summer Cloud Ocean Study (ASCOS), Atmos. Chem. Phys., 17, 6693-6704, https://doi.org/10.5194/acp-176693-2017, 2017.

Manners, J., Hill, P. G., and Ex, D.: Unified Model Documentation Paper 023 The Radiation Code, Met Office, 2016.

Martin, G. M., Johnson, D. W., and Spice, A.: The Measurement and Parameterization of Effective Radius of Droplets in Warm Stratocumulus Clouds, J. Atmos. Sci., 51, 1823-1842, https://doi.org/10.1175/15200469(1994)051<1823:TMAPOE>2.0.CO;2, 1994.

Martin, M., Chang, R. Y.-W., Sierau, B., Sjogren, S., Swietlicki, E., Abbatt, J. P. D., Leck, C., and Lohmann, U.: Cloud condensation nuclei closure study on summer arctic aerosol, Atmos. Chem. Phys., 11, 11335-11350, https://doi.org/10.5194/acp-11-113352011, 2011.

Mauritsen, T., Sedlar, J., Tjernström, M., Leck, C., Martin, M., Shupe, M., Sjogren, S., Sierau, B., Persson, P. O. G., Brooks, I. M., and Swietlicki, E.: An Arctic CCN-limited cloud-aerosol regime, Atmos. Chem. Phys., 11, 165-173, https://doi.org/10.5194/acp-11-165-2011, 2011.

McFarquhar, G. M., Ghan, S., Verlinde, J., Korolev, A., Strapp, J. W., Schmid, B., Tomlinson, J. M., Wolde, M., Brooks, S. D., Cziczo, D., Dubey, M. K., Fan, J., Flynn, C., Gultepe, I., Hubbe, J., Gilles, M. K., Laskin, A., Lawson, P., Leaitch, W. R., Liu, P., Liu, X., Lubin, D., Mazzoleni, C., MacDonald, A. M., Moffet, R. C., Morrison, H., Ovchinnikov, M., Shupe, M. D., Turner, D. D., Xie, S., Zelenyuk, A., Bae, K., Freer, M., and Glen, A.: Indirect and semi-direct aerosol campaign: The impact of arctic aerosols on clouds, B. Am. Meteorol. Soc., 92, 183-201, https://doi.org/10.1175/2010BAMS2935.1, 2011.

Mellor, G. L. and Yamada, T.: A Hierarchy of Turbulence Closure Models for Planetary Boundary Layers, J. Atmos. Sci., 31, 1791-1806, https://doi.org/10.1175/15200469(1974)031<1791:AHOTCM>2.0.CO;2, 1974.
Miltenberger, A. K., Field, P. R., Hill, A. A., Rosenberg, P., Shipway, B. J., Wilkinson, J. M., Scovell, R., and Blyth, A. M.: Aerosol-cloud interactions in mixed-phase convective clouds Part 1: Aerosol perturbations, Atmos. Chem. Phys., 18, 3119 3145, https://doi.org/10.5194/acp-18-3119-2018, 2018.

Morrison, H., Shupe, M. D., and Curry, J. A.: Modeling clouds observed at SHEBA using a bulk microphysics parameterization implemented into a single-column model, J. Geophys. Res.-Atmos., 108, 4255, https://doi.org/10.1029/2002JD002229, 2003.

Morrison, H., Curry, J. A., and Khvorostyanov, V. I.: A New Double-Moment Microphysics Parameterization for Application in Cloud and Climate Models. Part I: Description, J. Atmos. Sci., 62, 1665-1677, https://doi.org/10.1175/JAS3446.1, 2005a.

Morrison, H., Shupe, M. D., Pinto, J. O., and Curry, J. A.: Possible roles of ice nucleation mode and ice nuclei depletion in the extended lifetime of Arctic mixed-phase clouds, Geophys. Res. Lett., 32, 1-5, https://doi.org/10.1029/2005GL023614, 2005 b.

Morrison, H., Zuidema, P., Ackerman, A. S., Avramov, A., De Boer, G., Fan, J., Fridlind, A. M., Hashino, T., Harrington, J. Y., Luo, Y., Ovchinnikov, M., and Shipway, B.: Intercomparison of cloud model simulations of Arctic mixed-phase boundary layer clouds observed during SHEBA/FIRE-ACE, J. Adv. Model. Earth Sy., 3, 1-23, https://doi.org/10.1029/2011MS000066, 2011.

Nakanishi, M. and Niino, H.: An improved Mellor-Yamada Level-3 model: Its numerical stability and application to a regional prediction of advection fog, Bound.-Lay. Meteorol., 119, 397-407, https://doi.org/10.1007/s10546-005-9030-8, 2006.

Nenes, A. and Seinfeld, J. H.: Parameterization of cloud droplet formation in global climate models, J. Geophys. Res., 108, 4415, https://doi.org/10.1029/2002JD002911, 2003.

Ovchinnikov, M., Korolev, A., and Fan, J.: Effects of ice number concentration on dynamics of a shallow mixedphase stratiform cloud, J. Geophys. Res.-Atmos., 116, 1-15, https://doi.org/10.1029/2011JD015888, 2011.

Ovchinnikov, M., Ackerman, A. S., Avramov, A., Cheng, A., Fan, J., Fridlind, A. M., Ghan, S., Harrington, J., Hoose, C., Korolev, A., McFarquhar, G. M., Morrison, H., Paukert, M., Savre, J., Shipway, B. J., Shupe, M. D., Solomon, A., and Sulia, K.: Intercomparison of large-eddy simulations of Arctic mixed-phase clouds: Importance of ice size distribution assumptions, J. Adv. Model. Earth Sy., 6, 223-248, https://doi.org/10.1002/2013MS000282, 2014.

Paatero, J., Vaattovaara, P., Vestenius, M., Meinander, O., Makkonen, U., Kivi, R., Hyvärinen, A., Asmi, E., Tjernström, M., and Leck, C.: Finnish contribution to the Arctic summer cloud ocean study (ASCOS) expedition, Arctic ocean 2008, Geophysica, 45, 119-146, 2009.

Paukert, M. and Hoose, C.: Modeling immersion freezing with aerosol-dependent prognostic ice nuclei in Arctic mixed-phase clouds, J. Geophys. Res., 119, 9073-9092, https://doi.org/10.1002/2014JD021917, 2014.

Peters, G. P., Nilssen, T. B., Lindholt, L., Eide, M. S., Glomsrød, S., Eide, L. I., and Fuglestvedt, J. S.: Future emissions from shipping and petroleum activities in the Arctic, Atmos. Chem. Phys., 11, 5305-5320, https://doi.org/10.5194/acp-11-5305-2011, 2011.

Petters, M. D. and Kreidenweis, S. M.: A single parameter representation of hygroscopic growth and cloud condensa- 
tion nucleus activity, Atmos. Chem. Phys., 7, 1961-1971, https://doi.org/10.5194/acp-7-1961-2007, 2007.

Pinto, J. O.: Autumnal mixed-phase cloudy boundary layers in the Arctic, J. Atmos. Sci., 55, 2016-2038, https://doi.org/10.1175/15200469(1998)055<2016:AMPCBL>2.0.CO;2, 1998.

Possner, A., Zubler, E., Fuhrer, O., Lohmann, U., and Schär, C.: A Case Study in Modeling Low-Lying Inversions and Stratocumulus Cloud Cover in the Bay of Biscay, Weather Forecast., 29, 289-304, https://doi.org/10.1175/WAF-D-13-00039.1, 2014.

Possner, A., Ekman, A. M. L., and Lohmann, U.: Cloud response and feedback processes in stratiform mixed-phase clouds perturbed by ship exhaust, Geophys. Res. Lett., 44, 1964-1972, https://doi.org/10.1002/2016GL071358, 2017.

Prenni, A. J., Harrington, J. Y., Tjernstöm, M., DeMott, P. J., Avramov, A., Long, C. N., Kreidenweis, S. M., Olsson, P. Q., and Verlinde, J.: Can ice-nucleating aerosols affect arctic seasonal climate?, B. Am. Meteorol. Soc., 88, 541-550, https://doi.org/10.1175/BAMS-88-4-541, 2007.

Ritter, B. and Geleyn, J.-F.: A Comprehensive Radiation Scheme for Numerical Weather Prediction Models with Potential Applications in Climate Simulations, Mon. Weather Rev., 120, 303-325, https://doi.org/10.1175/15200493(1992)120<0303:ACRSFN>2.0.CO;2, 1992.

Sand, M., Samset, B. H., Balkanski, Y., Bauer, S., Bellouin, N., Berntsen, T. K., Bian, H., Chin, M., Diehl, T., Easter, R., Ghan, S. J., Iversen, T., Kirkevåg, A., Lamarque, J.-F., Lin, G., Liu, X., Luo, G., Myhre, G., Noije, T. V., Penner, J. E., Schulz, M., Seland, Ø., Skeie, R. B., Stier, P., Takemura, T., Tsigaridis, K., Yu, F., Zhang, K., and Zhang, H.: Aerosols at the poles: an AeroCom Phase II multi-model evaluation, Atmos. Chem. Phys., 17, 12197-12218, https://doi.org/10.5194/acp-17-121972017, 2017.

Savre, J., Ekman, A. M. L., and Svensson, G.: Technical note: Introduction to MIMICA, a large-eddy simulation solver for cloudy planetary boundary layers, J. Adv. Model. Earth Sy., 6, 1-20, https://doi.org/10.1002/2013MS000292, 2014.

Sedlar, J., Tjernström, M., Mauritsen, T., Shupe, M. D., Brooks, I. M., Persson, P. O. G., Birch, C. E., Leck, C., Sirevaag, A., and Nicolaus, M.: A transitioning Arctic surface energy budget: The impacts of solar zenith angle, surface albedo and cloud radiative forcing, Clim. Dynam., 37, 1643-1660, https://doi.org/10.1007/s00382-010-0937-5, 2011.

Seifert, A. and Beheng, K. D.: A two-moment cloud microphysics parameterization for mixed-phase clouds. Part 1: Model description, Meteorol. Atmos. Phys., 92, 45-66, https://doi.org/10.1007/s00703-005-0112-4, 2006.

Seifert, A., Nuijens, L., and Stevens, B.: Turbulence effects on warm-rain autoconversion in precipitating shallow convection, Q. J. Roy. Meteor. Soc., 136, 1753-1762, https://doi.org/10.1002/qj.684, 2010.

Serreze, M. C. and Stroeve, J. C.: Arctic sea ice trends, variability and implications for seasonal ice forecasting, Philos. T. Roy. Soc. A, 373, 20140159, https://doi.org/10.1098/rsta.2014.0159, 2015.

Shindell, D. and Faluvegi, G.: Climate response to regional radiative forcing during the twentieth century, Nat. Geosci., 2, 294-300, https://doi.org/10.1038/ngeo473, 2009.

Shupe, M. D., Persson, P. O. G., Brooks, I. M., Tjernström, M., Sedlar, J., Mauritsen, T., Sjogren, S., and Leck, C.: Cloud and bound- ary layer interactions over the Arctic sea ice in late summer, Atmos. Chem. Phys., 13, 9379-9399, https://doi.org/10.5194/acp13-9379-2013, 2013.

Shupe, M. D., Turner, D. D., Zwink, A., Thieman, M. M., Mlawer, E. J., and Shippert, T.: Deriving arctic cloud microphysics at Barrow, Alaska: Algorithms, results, and radiative closure, J. Appl. Meteorol. Clim., 54, 1675-1689, https://doi.org/10.1175/JAMCD-15-0054.1, 2015.

Solomon, A., Morrison, H., Persson, O., Shupe, M. D., and Bao, J.-W.: Investigation of Microphysical Parameterizations of Snow and Ice in Arctic Clouds during M-PACE through ModelObservation Comparisons, Mon. Weather Rev., 137, 3110-3128, https://doi.org/10.1175/2009MWR2688.1, 2009.

Solomon, A., Feingold, G., and Shupe, M. D.: The role of ice nuclei recycling in the maintenance of cloud ice in Arctic mixedphase stratocumulus, Atmos. Chem. Phys., 15, 10631-10643, https://doi.org/10.5194/acp-15-10631-2015, 2015.

Sotiropoulou, G., Sedlar, J., Forbes, R., and Tjernström, M.: Summer Arctic clouds in the ECMWF forecast model: an evaluation of cloud parameterization schemes, Q. J. Roy. Meteor. Soc., 142, 387-400, https://doi.org/10.1002/qj.2658, 2015.

Steppeler, J., Doms, G., Schättler, U., Bitzer, H. W., Gassmann, A., U., D., and Gregoric, G.: Meso-gamma scale forecasts using the nonhydrostatic model LM, Meteorol. Atmos. Phys., 82, 75-96, https://doi.org/10.1007/s00703-001-0592-9, 2003.

Stevens, B., Moeng, C., and Sullivan, P.: Large-eddy simulations of radiatively driven convection: Sensitivities to the representation of small scales, J. Atmos. Sci., 56, 3963-3984, https://doi.org/10.1175/15200469(1999)056<3963:LESORD>2.0.CO;2, 1999.

Stevens, B., Moeng, C.-H., Ackerman, A. S., Bretherton, C. S., Chlond, A., de Roode, S., Edwards, J., Golaz, J.-C., Jiang, H., Khairoutdinov, M., Kirkpatrick, M. P., Lewellen, D. C., Lock, A., Müller, F., Stevens, D. E., Whelan, E., and Zhu, P.: Evaluation of Large-Eddy Simulations via Observations of Nocturnal Marine Stratocumulus, Mon. Weather Rev., 133, 1443-1462, https://doi.org/10.1175/MWR2930.1, 2005.

Stevens, R. G., Loewe, K., Dearden, C., Dimitrelos, A., Possner, A., Eirund, G. K., Raatikainen, T., Hill, A. A., Shipway, B. J., Wilkinson, J., Romakkaniemi, S., Tonttila, J., Laaksonen, A., Korhonen, H., Connolly, P., Lohmann, U., Hoose, C., Ekman, A. M. L., Carslaw, K. S., and Field, P. R.: Model output from "A model intercomparison of CCN-limited tenuous clouds in the high Arctic" [Data set], Zenodo, https://doi.org/10.5281/zenodo.1326922, 2018.

Stratton, R. A., Willett, M. R., Derbyshire, S., Wong, R., and Whithall, M.: Unified Model Documentation Paper 027 Convection Schemes, Met Office, 2015.

Struthers, H., Ekman, A. M. L., Glantz, P., Iversen, T., Kirkevåg, A., Mårtensson, E. M., Seland, Ø., and Nilsson, E. D.: The effect of sea ice loss on sea salt aerosol concentrations and the radiative balance in the Arctic, Atmos. Chem. Phys., 11, 3459-3477, https://doi.org/10.5194/acp-11-3459-2011, 2011.

Tjernström, M., Leck, C., Persson, P. O. G., Jensen, M. L., Oncley, S. P., and Targino, A.: The summertime arctic atmosphere: Meteorological measurements during the Arctic Ocean Experiment 2001, B. Am. Meteorol. Soc., 85, 1305-1321, https://doi.org/10.1175/BAMS-85-9-1305, 2004. 
Tjernström, M., Birch, C. E., Brooks, I. M., Shupe, M. D., Persson, P. O. G., Sedlar, J., Mauritsen, T., Leck, C., Paatero, J., Szczodrak, M., and Wheeler, C. R.: Meteorological conditions in the central Arctic summer during the Arctic Summer Cloud Ocean Study (ASCOS), Atmos. Chem. Phys., 12, 6863-6889, https://doi.org/10.5194/acp-12-6863-2012, 2012.

Tjernström, M., Leck, C., Birch, C. E., Bottenheim, J. W., Brooks, B. J., Brooks, I. M., Bäcklin, L., Chang, R. Y.-W., de Leeuw, G., Di Liberto, L., de la Rosa, S., Granath, E., Graus, M., Hansel, A., Heintzenberg, J., Held, A., Hind, A., Johnston, P., Knulst, J., Martin, M., Matrai, P. A., Mauritsen, T., Müller, M., Norris, S. J., Orellana, M. V., Orsini, D. A., Paatero, J., Persson, P. O. G., Gao, Q., Rauschenberg, C., Ristovski, Z., Sedlar, J., Shupe, M. D., Sierau, B., Sirevaag, A., Sjogren, S., Stetzer, O., Swietlicki, E., Szczodrak, M., Vaattovaara, P., Wahlberg, N., Westberg, M., and Wheeler, C. R.: The Arctic Summer Cloud Ocean Study (ASCOS): overview and experimental design, Atmos. Chem. Phys., 14, 2823-2869, https://doi.org/10.5194/acp14-2823-2014, 2014.

Tjernström, M., Shupe, M. D., Brooks, I. M., Persson, P. O. G., Prytherch, J., Salisbury, D. J., Sedlar, J., Achtert, P., Brooks, B. J., Johnston, P. E., Sotiropoulou, G., and Wolfe, D.: Warm-air advection, air mass transformation and fog causes rapid ice melt, Geophys. Res. Lett., 42, 5594-5602, https://doi.org/10.1002/2015GL064373, 2015.

Tonttila, J., Maalick, Z., Raatikainen, T., Kokkola, H., Kühn, T., and Romakkaniemi, S.: UCLALES-SALSA v1.0: a largeeddy model with interactive sectional microphysics for aerosol, clouds and precipitation, Geosci. Model Dev., 10, 169-188, https://doi.org/10.5194/gmd-10-169-2017, 2017.

Uttal, T., Curry, J. A., McPhee, M. G., Perovich, D. K., Moritz, R. E., Maslanik, J. A., Guest, P. S., Stern, H. L., Moore, J. A., Turenne, R., Heiberg, A., Serreze, M. C., Wylie, D. P., Persson, O. G., Paulson, C. A., Halle, C., Marison, J. H., Wheeler, P. A., Makshtas, A., Welch, H., Shupe, M. D., Intrieri, J. M., Stamnes, K., Lindsey, R. W., Pinkel, R., Pegau, W. S., Stanton, T. P., and Grenfeld, T. C.: Surface heat budget of the arctic ocean, B. Am. Meteorol. Soc., 83, 255-275, https://doi.org/10.1175/15200477(2002)083<0255:SHBOTA>2.3.CO;2, 2002.

Vaughan, D., Comiso, J., Allison, I., Carrasco, J., Kaser, G., Kwok, R., Mote, P., Murray, T., Paul, F., Ren, J., Rignot, E., Solomina, O., Steffen, K., and Zhang, T.: Observations: Cryosphere, in: Climate Change 2013: The Physical Science Basis. Contribution of Working Group I to the Fifth Assessment Report of the Intergovernmental Panel on Climate Change, edited by: Stocker, T., Qin, D., Plattner, G.K., Tignor, M., Allen, S., Boschung, J., Nauels, A., Xia, Y., Bex, V., and Midgley, P., Cambridge University Press, Cambridge, United Kingdom and New York, NY, USA, 317-382, https://doi.org/10.1017/CBO9781107415324.012, 2013.
Verlinde, J., Harrington, J. Y., McFarquhar, G. M., Yannuzzi, V. T., Avramov, A., Greenberg, S., Johnson, N., Zhang, G., Poellot, M. R., Mather, J. H., Turner, D. D., Eloranta, E. W., Zak, B. D., Prenni, A. J., Daniel, J. S., Kok, G. L., Tobin, D. C., Holz, R., Sassen, K., Spangenberg, D., Minnis, P., Tooman, T. P., Ivey, M. D., Richardson, S. J., Bahrmann, C. P., Shupe, M., DeMott, P. J., Heymsfield, A. J., and Schofield, R.: The mixed-phase arctic cloud experiment, B. Am. Meteorol. Soc., 88, 205-221, https://doi.org/10.1175/BAMS-88-2-205, 2007.

Vogel, B., Vogel, H., Bäumer, D., Bangert, M., Lundgren, K., Rinke, R., and Stanelle, T.: The comprehensive model system COSMOART - Radiative impact of aerosol on the state of the atmosphere on the regional scale, Atmos. Chem. Phys., 9, 8661-8680, https://doi.org/10.5194/acp-9-8661-2009, 2009.

Wang, C. and Chang, J. S.: A Three-Dimensional Numerical Model of Cloud Dynamics, Microphysics, and Chemistry 1. Concepts and Formulation, J. Geophys. Res., 98, 14827-14844, 1993.

Wesslén, C., Tjernström, M., Bromwich, D. H., de Boer, G., Ekman, A. M. L., Bai, L.-S., and Wang, S.-H.: The Arctic summer atmosphere: an evaluation of reanalyses using ASCOS data, Atmos. Chem. Phys., 14, 2605-2624, https://doi.org/10.5194/acp14-2605-2014, 2014.

Westwater, E. R., Han, Y., Shupe, M. D., and Matrosov, S. Y.: Analysis of integrated cloud liquid and precipitable water vapor retrievals from microwave radiometers during the Surface Heat Budget of the Arctic Ocean project, J. Geophys. Res.-Atmos., 106, 32019-32030, https://doi.org/10.1029/2000JD000055, 2001.

Young, G., Jones, H. M., Choularton, T. W., Crosier, J., Bower, K. N., Gallagher, M. W., Davies, R. S., Renfrew, I. A., Elvidge, A. D., Darbyshire, E., Marenco, F., Brown, P. R. A., Ricketts, H. M. A., Connolly, P. J., Lloyd, G., Williams, P. I., Allan, J. D., Taylor, J. W., Liu, D., and Flynn, M. J.: Observed microphysical changes in Arctic mixed-phase clouds when transitioning from sea ice to open ocean, Atmos. Chem. Phys., 16, 13945-13967, https://doi.org/10.5194/acp-16-13945-2016, 2016.

Young, G., Connolly, P. J., Jones, H. M., and Choularton, T. W.: Microphysical sensitivity of coupled springtime Arctic stratocumulus to modelled primary ice over the ice pack, marginal ice, and ocean, Atmos. Chem. Phys., 17, 4209-4227, https://doi.org/10.5194/acp-17-4209-2017, 2017.

Young, G., Connolly, P. J., Dearden, C., and Choularton, T. W.: Relating large-scale subsidence to convection development in Arctic mixed-phase marine stratocumulus, Atmos. Chem. Phys., 18, 1475-1494, https://doi.org/10.5194/acp-18-1475-2018, 2018. 